\title{
The Production-Side Approach to Estimating Embodied Technological Change ${ }^{1}$
}

\author{
Plutarchos Sakellaris \\ University of Maryland, University of Ioannina, and \\ Federal Reserve Board \\ and \\ Daniel J. Wilson \\ University of Maryland
}

\section{DECEMBER 2000-PRELIMINARY}

\begin{abstract}
:
We estimate the rate of embodied technological change directly from plant-level manufacturing data on current output and input choices along with histories on their vintages of equipment investment. Our estimates range between 8 and 17 percent for the typical U.S. manufacturing plant during the years 1972-1996. Any number in this range is substantially larger than is conventionally accepted with some important implications. First, the role of investmentspecific technological change as an engine of growth is even larger than previously estimated. Second, existing producer durable price indices do not adequately account for quality change. As a result, measured capital stock growth is biased. Third, if accurate, the Hulten and Wykoff (1981) economic depreciation rates may primarily reflect obsolescence.

${ }^{1}$ Correspondence: plutarch@electra.umd.edu; wilson@inforum.umd.edu. We would like to thank seminar participants at the Federal Reserve Board; the Center for Economic Studies (CES), U.S. Census Bureau; Inforum; and the University of Maryland for useful comments. Plutarchos Sakellaris would like to thank the staff of the Industrial Output Section of the Federal Reserve Board for their hospitality while he was working on this paper. Daniel Wilson thanks Clopper Almon and the staff of Inforum for their generous support, financial and otherwise, of this research. The data used in this paper were collected under the provisions of Title 13 US Code and are only available at the CES. The research in this paper was conducted by the authors as Research Associates at the CES. The views expressed here do not represent those of the Board of Governors of the Federal Reserve System, its staff, or the U.S. Census Bureau.
\end{abstract}




\section{Introduction}

The seminal papers by Johansen (1959) and Solow (1960) argued that more recent vintages of capital may embody technological advances that make them "better" than older vintages. "Better", or equivalently "of higher quality", means displaying higher productivity after adjusting for wear and tear. An important implication of this idea is that investment is essential in reaping benefits from some part of technological progress. Recently, there has been significant research on the role of capital-embodied (also known as investment-specific) technological change as a source of economic growth and fluctuations. Hulten (1992) shows that the failure to adjust capital for quality change has the effect of suppressing the quality effects into the conventional total-factor-productivity residual. He also finds that about 20 percent of the residual growth in quality-adjusted output of U.S. manufacturing is due to embodied technological change. Greenwood, Hercowitz, and Krusell (1997) find that embodied technological change accounts for close to 60 percent of the growth of output per hours worked in the U.S. economy. ${ }^{2}$

Both of these studies use Gordon's (1990) price index for producer durable equipment (PDE) and identify the embodied technological growth with the rate of decline of this index relative to a base index that is assumed not to contain any quality adjustment. This puts the rate of embodied technological change at about 3 percent for the years 1954 to 1990.

In this paper we implement a production-side approach to estimate the rate of embodied technological change from data on manufacturing plants' output and input choices together with histories on their vintages of investment. We arrive at the conclusion that the average rate of embodied technological change has been much higher in U.S. manufacturing during the years 1972-1996. Our estimates range between 8 and 17 percent. With the exception of the high rates implied by Bahk and Gort's (1993) findings, any number in this range is substantially larger the conventional wisdom in this area. This has several important implications. First, the role of investment-specific technological change as an engine of growth is even larger than previously estimated. Second, existing producer durable price indices substantially mismeasure quality change, yielding biased measures of capital stock growth. Lastly, assuming Hulten and Wykoff's (1981) estimates of economic depreciation, which have since been adopted by the U.S. Bureau of Economic Analysis (BEA), are correct, our estimates suggest that obsolescence is the most important factor in the decline of an average capital asset's value over time.

${ }^{2}$ It should be noted that Greenwood, el al. (1997) make a distinction between "embodied" and "investment-specific" technological change by defining the latter as either quality improvements in capital or decreases in the cost of producing capital, whereas they define embodied technological change as only quality improvements. We make no such distinction in this paper and use these terms interchangeably. Our estimates of embodied technological change should reflect the combined effect of the these two phenomena. 


\section{A two-sector model of investment-specific technological change ${ }^{3}$}

In order to formalize the concept of capital-embodied technological change we consider a two-sector model where one sector produces investment goods $(\widetilde{i})$ and the other produces consumption goods (c). Each good is produced using capital $(\mathrm{k})$ and labor $(\mathrm{l})$ as inputs according to the following production functions:

$$
\begin{gathered}
\tilde{\dot{j}}_{\mathrm{t}}=\mathrm{z}_{\mathrm{t}} \mathrm{q}_{\mathrm{t}} \widetilde{\mathrm{K}}_{\widetilde{\mathrm{i}, \mathrm{t}}}^{\alpha} \mathbf{1}_{\widetilde{\mathrm{i}, \mathrm{t}}}^{1-\alpha} \\
\mathrm{c}_{\mathrm{t}}=\mathrm{z}_{\mathrm{t}} \widetilde{\mathrm{K}}_{\mathrm{c}, \mathrm{t}}^{\alpha} 1_{\mathrm{c}, \mathrm{t}}^{1-\alpha}
\end{gathered}
$$

where $\mathrm{z}$ is the level of technology common to both sectors whereas $\mathrm{q}$ is technological level specific to the investment sector ${ }^{4}$. A " $~$ " denotes that the variable is defined in terms of efficiency units. For simplicity, $\alpha$, the elasticity of output with respect to capital is assumed to be the same in both sectors. ${ }^{5}$ Assume that all factors of production are perfectly mobile across sectors and that perfect competition holds in all markets. Then, as a result of factor price equalization, the price of investment goods relative to consumption goods

is: $\mathrm{P}_{\mathrm{t}}^{\widetilde{\mathrm{i}}} / \mathrm{P}_{\mathrm{t}}^{\mathrm{c}}=1 / \mathrm{q}_{\mathrm{t}}$. Thus, one may compute the rate of growth of investment-specific (capital-embodied) technological change from the rate of decline in the relative price of investment goods.

Figure 1 graphs the Personal Consumption Expenditures (PCE) deflator from the National Income and Product Accounts (NIPA) and an average equipment-investment price index for manufacturing. The latter is an average, over our plant-level sample, of the 3-digit industry equipment-investment deflators constructed by the Federal Reserve Board (FRB) using industry investment-by-asset type data from the BEA and Producer Price Indexes (PPI) for asset types $^{6}$. Oddly enough, these two indexes grow about the same rate between 1972 and $1996^{7}$.

${ }^{3}$ The exposition in this section follows Hornstein and Krusell (1996), Greenwood et al. (1997), and Hercowitz (1998). For clarity, we do not make a distinction here between structures and equipment investment, though in the empirical work this distinction will be crucial.

${ }^{4}$ Greenwood et al. (1997) discuss conditions under which the economy exhibits balanced growth with or without exogenous technological change.

${ }^{5}$ Hornstein and Krusell (1996) show the implications of allowing $\alpha$ to differ by sector.

${ }^{6}$ The FRB industry-level deflators are matched to the plant-year records in our sample according to the 3-digit industry to which a plant belonged in that year. For each year between 1972 and 1996 (the investment years covered by our sample), we take the within-year, crosssectional mean of the equipment-investment price deflators. Thus, for any particular year, this 
Does this mean that there was no embodied technological change during this period? As we detail in the next section, several authors provided a negative answer arguing that the official price indexes for PDE grow too fast as a result of mismeasurement. They use, instead, equipment-investment price indexes constructed by Gordon (1990) to reflect quality change. However, the comparison of the above two price indexes is not the only way to ascertain the importance of embodiment. We provide below and in section (4) an alternative approach relying on data on produced output and utilized inputs .

Since the production function is homogeneous of degree one and the capital-labor ratio is equal across sectors one can write total output in terms of consumption goods as:

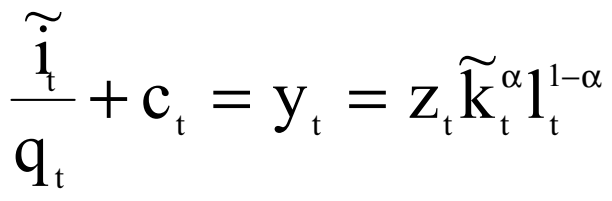

Note that capital input, $\widetilde{\mathrm{K}}$, in the above expression is defined in efficiency units (i.e. in terms of investment goods):

$$
\widetilde{\mathrm{k}}_{\mathrm{t}}=(1-\delta) \widetilde{\mathrm{k}}_{\mathrm{t}-1}+\widetilde{\mathrm{i}}_{\mathrm{t}}
$$

where $\delta$ is the geometric rate of physical depreciation ${ }^{8}$. The above expression for total output demonstrates that this two-sector economy is equivalent to a one-sector economy where (disembodied) technological change is captured by $\mathrm{z}_{\mathrm{t}}$ and output saved as capital is enhanced (in terms of efficiency) by capital-embodied technological change, $\mathrm{q}_{\mathrm{t}}$. The society can only take advantage of this latter form of technological change by forgoing consumption and investing in capital.

To see this more clearly, define investment in terms of consumption goods:

$\dot{i}_{t}=\widetilde{i}_{t} / q_{t}$. Then, the capital transition equation may be written as:

$$
\widetilde{k}_{t}=(1-\delta) \widetilde{k}_{t-1}+i_{t} q_{t}
$$

Once again, in order to construct the capital stock correctly one needs to adjust each vintage of

mean can be thought of as a weighted average of the FRB's 3-digit deflators where the weights are the fraction of our sample in each 3-digit industry. An unweighted average is nearly identical.

${ }^{7}$ However, the behavior is distinctly different in two subperiods. Between 1972 and 1981 equipment-investment prices rose 2.25 percent per year compared to consumption goods whereas from 1982 to 1996 they fell 1.67 percent per year.

${ }^{8}$ This concept comes in many other names, for example, physical decay, or depreciation from use. It is not equivalent to economic depreciation. 
investment for quality change that is due to investment-specific technological change. Equations (3) and (5) provide an alternative way to estimating embodied technological change, $q_{t}$, without the use of a price index for equipment investment. One may estimate the q series econometrically with plant level data, say, on output and current and past investment measured in terms of consumption in addition to data on labor input.

Equations (3) and (4) may be written equivalently as:

$$
\begin{gathered}
\mathrm{y}_{\mathrm{t}}=\mathrm{z}_{\mathrm{t}} \mathrm{q}_{\mathrm{t}}^{\alpha} \mathrm{k}_{\mathrm{t}}^{\alpha} \mathrm{l}_{\mathrm{t}}^{1-\alpha} \\
\mathrm{k}_{\mathrm{t}}=\left[(1-\delta) /\left(1+\gamma_{\mathrm{t}}\right)\right] \cdot \mathrm{k}_{\mathrm{t}-1}+\mathrm{i}_{\mathrm{t}}
\end{gathered}
$$

To see this, let $\mathrm{q}_{\mathrm{t}} / \mathrm{q}_{\mathrm{t}-1}=1+\gamma_{\mathrm{t}}$ and $\mathrm{k}_{\mathrm{t}}=\mathrm{K}_{\mathrm{t}} / \mathrm{q}_{\mathrm{t}}$. The system of (6) and (7) provides an alternative way of constructing the capital stock and decomposing growth in output. Investment flows are unadjusted for quality improvement but depreciation gets augmented by a term, $1 /\left(1+\gamma_{t}\right)$, that reflects obsolescence due to investment-specific technological change 9 . Note, however, that the residual in this decomposition known as total factor productivity (TFP) cannot be attributed to investment-neutral technological change, $\mathrm{z}$, alone.

To drive home the point that there are many different but equivalent ways of measuring aggregate output and capital, and accounting for growth we present now yet another alternative to equations (3) and (4). Suppose that we measured aggregate output, Y, by summing investment goods production expressed in efficiency units and consumption goods production in consumption units. Indeed, this is the approach the NIPA attempts to follow. The national income accounting identity would then be written as:

$$
\widetilde{\mathrm{i}}_{\mathrm{t}}+\mathrm{c}_{\mathrm{t}}=\mathrm{Y}_{\mathrm{t}}=\left[\left(1-\mu_{\mathrm{t}}\right)+\mu_{\mathrm{t}} \mathrm{q}_{\mathrm{t}}\right] \cdot \mathrm{z}_{\mathrm{t}} \widetilde{\mathrm{k}}_{\mathrm{t}}^{\alpha} 1_{\mathrm{t}}^{1-\alpha}
$$

where $\mu_{t}=\widetilde{\mathrm{k}}_{\widetilde{\mathrm{i}}_{, t}} / \widetilde{\mathrm{K}}_{\mathrm{t}}$ is the fraction of aggregate capital stock, measured in efficiency units, devoted to investment goods production. Equivalently, $\mu_{t}$, may be measured as the ratio of the output of the investment sector, $\widetilde{i}$, to total output, y, both measured in terms of consumption,

$$
\mu_{t}=\frac{\widetilde{\dot{i}_{t}} / q_{t}}{c_{t}+\widetilde{i}_{t} / q_{t}}
$$

The TFP that one obtains after applying the growth accounting decomposition with these measures of aggregate output (equation 8) and capital stock (equation 4) is a weighted average of the TFP in each of the two sectors where the weight is given by $\mu_{\mathrm{t}}$.

${ }^{9}$ See Solow (1960) for extensive discussion of the implications of this result. 


\section{Related Literature}

One could classify the set of related papers into two camps. Most of the recent contributions use Gordon's (1990) quality-adjusted price indices for PDE in order to identify embodied technological change and then answer important questions related to economic growth or fluctuations in the U.S. The second camp contains older contributions that estimated embodied technological change using data on production and capital stock age using an approach due to Nelson (1964). We review these two camps briefly here and point out the main differences of our approach.

\section{Price-Based Estimates of Embodied Technological Change}

Gordon (1990) is a major study aimed at correcting mismeasurement in equipment price indices due to quality change. He provides quality-adjusted price indices for 22 types of equipment and their components. Hulten (1992) was the first to use these series in order to identify embodied technological change. He constructed a share-weighted average of Gordon's indices as well as one for the corresponding price indices published by BLS. Taking the ratio of the two, he calculated the average annual growth rate of embodied technological change to be 3.44 percent for U.S. manufacturing during 1949-1983. As a result, he attributed about 20 percent of the residual growth of quality-adjusted manufacturing gross output to embodied technological change.

Various papers followed Hulten (1992) in using Gordon's data but differed in the methodology employed. Greenwood et al. (1997) argued that the baseline index for comparison should be the implicit price deflator for non-durable consumption goods. This had very little affect on their estimate of embodied technological change. Three other differences in methodology, however, were important. Greenwood et al. (1997) advocated that output not be adjusted for quality change, that value added data be used in place of gross output and that a general equilibrium approach be used that accounts for input growth due to embodied technological change. They found that embodied technological change contributed about 58 percent of all output growth in the U.S. between 1954 and $1990^{10}$.

Hornstein and Krusell (1996) and Greenwood and Yorukoglu (1997), among others, note that the Gordon index points to a large increase in the rate of embodied technological change after $1973^{11}$. They argue that this increased technological change and the adjustment processes necessitated by it are largely responsible for the post-1973 measured slowdown in productivity growth.

Greenwood et al. (2000) use Gordon's data to investigate the importance of embodied technological change for postwar U.S. aggregate fluctuations. They document a negative comovement between relative price of equipment and equipment investment. Their analysis

\footnotetext{
${ }^{10}$ Disembodied change provided the rest. The authors actually use the terminology investment-specific versus neutral technological change.

${ }^{11}$ This increase is about 25 percent. See, e.g., Hornstein and Krusell (1996) p. 231.
} 
suggests that about 30 percent of output fluctuations are due to shocks in this relative price. ${ }^{12}$

The practice of using Gordon's (1990) quality-adjusted price indices for PDE in order to identify embodied technological change is not uncontroversial. Gordon (1996) takes issue with it. He claims that differences between his indices and the official ones are not entirely due to quality change. He offers as an example the traditional substitution bias introduced by a change in the relative prices of goods. Furthermore, he continues, quality adjustment may arise for reasons unrelated to embodied technological change. For example, an energy price increase may lead consumers to shift from inexpensive and energy-inefficient air conditioners to expensive and energy-efficient ones. The latter are also more costly to produce at any given level of technology in the equipment-producing sector (denoted $\mathrm{q}_{\mathrm{t}} \mathrm{z}_{\mathrm{t}}$ in our two-sector model) and do not necessarily represent an increase in technology ${ }^{13}$. Given these problems, it seems fruitful to examine alternative methods of estimating embodied technological change.

\section{Production-Based Estimates of Embodied Technological Change}

Nelson (1964) developed a variant of Solow's (1960) embodiment model that illustrated the relationship between the rate of embodied technological change and the average age of capital. He showed that, to an approximation, the log of efficiency-adjusted capital ( $\widetilde{\mathrm{K}})$ is proportional to a time trend plus the difference of $\gamma \mathrm{a}_{\mathrm{t}}$ and the $\log$ of unadjusted capital $(\mathrm{k})$, where $\mathrm{a}_{\mathrm{t}}$ is the average age of the unadjusted capital stock. Thus, a standard production function estimation (in logs) provides an estimate of embodied technological change by dividing the coefficient on average age by the coefficient on capital stock. Bahk and Gort (1993) study a sample of young manufacturing plants and find that a 1-year drop in average age is associated with between a 2.5 and a 3.5 percent rise in the plant's gross output (See their Table 1 and p. 571). Assuming a one-sixth share weight for capital in the production function of gross output, these results correspond to a 15-21 percent annual rate of growth of embodied technological change. This is five to seven times higher than the price-based estimates discussed above.

However, Bahk and Gort (1993) make the dubious assumption that maintenance outlays offset the effect of physical decay on the capital stock. Their capital stock construct is the sum of gross investments of all vintages without any adjustment for physical depreciation ${ }^{14}$. Their

\footnotetext{
${ }^{12}$ There are several related papers. See Greenwood et al. (2000) pp. 110-2 for a partial review.

${ }^{13}$ Gort and Wall (1998) argue that estimates of embodied technological change based on Gordon (1990) may be biased substantially towards zero (pp. 1658-9). They also point out another problem with the group of studies applying this methodology. While they adjust investment flows for quality change, they implicitly assume that economic depreciation rates, derived from Hulten and Wykoff (1981) and incorporated in the NIPA, measure only physical decay. This is unlikely to be true as these measures also incorporate obsolescence, in principle.

${ }^{14}$ While they admit that "this assumption is only at best an approximation of reality" (p.566) they do not provide concrete supporting evidence for it.
} 
estimates are best regarded as describing the joint impact of physical depreciation and embodiment. Our view is that physical decay occurs at a rate higher than zero.

For the sake of comparison, we also estimate the rate of embodied technological change using the average vintage specification. However, as discussed in Section 6 below, the Nelson approach relies on an approximation which is unreasonable for our data. Our framework is more general than Nelson's (1964) and is described in the next section ${ }^{15}$.

\section{Our Methodology}

The elusive holy grail of the embodiment literature has been independent estimates of embodied technological change. Our approach is to estimate that from production data. It involves exploiting the cross-sectional and time-series variation in plant-level historical investment distributions in order to estimate the relative levels of technology embodied in particular vintages of investment.

A simple example will help illustrate the basic concept. Consider two plants, A and B, both born in 1980 and observed continuously until 1989 (inclusive). Plant A expended 55\% of its lifetime (up to 1989) investment in 1980 and 5\% in each year thereafter. In contrast, plant B invested 55\% in 1989 and 5\% in each prior year. The plants are otherwise identical. One can exploit the variation in these two plants' vintage distributions in investment (net of physical decay) to estimate embodied technological change by comparing their output in 1989 . Doms \& Dunne (1998) provide empirical evidence of this kind of variation in investment. They find that over a 17-year period, 50\% of the average plant's investment is concentrated in 3 years (not necessarily consecutive). Furthermore, lumpy investment activity is not perfectly synchronized across plants.

We now formalize the production approach. Consider a Cobb-Douglas function for the production of plant output:

$$
\mathrm{y}_{\mathrm{it}}=\beta \cdot 1_{\mathrm{it}}+\theta \cdot \mathrm{m}_{\mathrm{it}}+\alpha \cdot \log \left(\mathrm{U}_{\mathrm{it}}^{\mathrm{P}} \mathrm{J}_{\mathrm{it}}\right)+\eta \cdot \log \left(\mathrm{U}_{\mathrm{it}}^{\mathrm{S}} \mathrm{S}_{\mathrm{it}}\right)+\zeta_{\mathrm{it}}
$$

where $\mathrm{y}$ is gross output, 1 is labor hours, $\mathrm{S}$ is the structures capital stock, $\mathrm{m}$ is materials (including energy expenditures), $\mathrm{J}$ is the equipment capital stock, I indexes plants, and $\mathrm{t}$ indexes year $^{16}$. Lowercase letters denote natural logs. The disturbance term, $\zeta_{\mathrm{it}}$ captures stochastic shocks to disembodied technology. It may contain both an aggregate and an idiosyncratic component. Equation (10) is the plant-level analogue of aggregate production function (3).

$\mathrm{U}^{J}$ and $\mathrm{U}^{\mathrm{S}}$ in equation (1) denote that the utilization rates of equipment and structures capital, respectively. To measure utilization, we follow Petropoulos (1999) who shows that

${ }^{15}$ A similar approach has been used before in a different but related context. Mark Doms (1996) applied the approach to a sample of "mini-mill" steel plants in order to estimate the physical depreciation schedule.

${ }^{16}$ All variables are in constant dollars unless stated otherwise. 
under certain reasonable conditions, the intensity of a plant's energy usage can be used as a proxy for capital utilization. Specifically (suppressing year and plant subscripts), we assume:

$$
\mathrm{U}^{\mathrm{J}}=(\mathrm{E} / \mathrm{J})^{\frac{1}{\tau_{\mathrm{J}}}} \text { and } \quad \mathrm{U}^{\mathrm{S}}=(\mathrm{E} / \mathrm{S})^{\frac{1}{\tau_{\mathrm{S}}}}
$$

where $\mathrm{E}$ denotes energy expenditures (fuel plus electricity). For purposes of identification, we assume that $\tau_{J}=\tau_{S}=\tau$. Substituting these expressions into the production function (1) and rearranging, we obtain

$$
\begin{aligned}
\mathrm{y}_{\mathrm{it}} & =\beta \cdot 1_{\mathrm{it}}+\theta \cdot \mathrm{m}_{\mathrm{it}}+[\alpha(\tau-1) / \tau] \cdot \log \left(\mathrm{J}_{\mathrm{it}}\right) \\
& +[\eta(\tau-1) / \tau] \cdot \log \left(\mathrm{S}_{\mathrm{it}}\right)+[(\alpha+\eta) / \tau] \cdot \mathrm{e}_{\mathrm{it}}+\zeta_{\mathrm{it}}
\end{aligned}
$$

where e denotes $\ln (\mathrm{E})$. Observable measures of $\mathrm{q}, 1, \mathrm{~m}$, and e can be readily constructed using variables in the LRD and price deflators from the NBER-CES Productivity Database (hereafter, NBER-CES). The construction of variables is described in the Data Appendix.

In this paper, we focus on the estimation of the rate of embodied technological change in equipment capital. Therefore, plants' structures capital stock is calculated according to the traditional perpetual inventory definition (see the Data Appendix) using historical structures investment from the LRD, price deflators from NBER-CES, and physical decay data from the FRB. Equipment capital, on the other hand, is a parameterized stream of past real equipment investment (net of physical decay):

$$
\mathrm{J}_{\mathrm{t}}=\sum_{\mathrm{s}=1}^{\mathrm{T}} \mathrm{I}_{\mathrm{t}-\mathrm{s}} \mathrm{D}_{\mathrm{t}, \mathrm{t}-\mathrm{s}} \phi_{\mathrm{t}-\mathrm{s}}
$$

where $T$ is the age of the plant, $I_{t-s}$ is real equipment investment of vintage t-s capital goods, $D_{t, t-s}$ is the fraction of one dollar's worth of vintage t-s investment that is still used in production in year $\mathrm{t}$, and $\phi_{t-s}$ is the level of embodied technology in equipment capital of vintage $\mathrm{t}$-s relative to some numeraire year's technology ${ }^{1718}$. This equation is analogous to equation (5) in the 2 -sector model. Equation (13) incorporates a one-year time-to-build assumption; that is, new investment is not put into operation until the following year. It takes time to build because of actual assembly requirements or because time is needed to train workers on how to use the new

${ }^{17}$ In terms of the two-sector model we described earlier, $\phi_{t}$ is the ratio of $q_{t}$ to $q_{0}$ where 0 refers to the numeraire year.

${ }^{18} \mathrm{We}$ assume that investment in vintage t-s capital goods is synonymous with new investment in year t-s. This is incorrect to the extent that there is investment in used capital of earlier vintages. Unfortunately, data on the vintage of a plant's used investment is not available in the LRD. This should have little effect on our results since used investment is typically a negligible part of total investment (new plus used). 
equipment ${ }^{19}$.

Substituting equation (13) into (12) yields the estimating model. Given the large number of parameters and the non-linearity of the model, we found that obtaining estimates (precise or otherwise) of $\phi_{t-s}$ was not possible in all but the most parsimonious of specifications. Thus, for the regressions reported in this paper, we simplify by assuming a constant geometric rate of embodied technological change. This changes the specification of $\mathrm{J}$ to:

$$
\mathrm{J}_{\mathrm{t}}=\sum_{\mathrm{s}=1}^{\mathrm{T}} \mathrm{I}_{\mathrm{t}-\mathrm{s}} \mathrm{D}_{\mathrm{t}, \mathrm{t}-\mathrm{s}}(1+\gamma)^{\mathrm{t}-\mathrm{s}-\mathrm{t}_{0}}
$$

where $\gamma$ is the rate of embodied technological change and $t_{0}$ is the numeraire year in which the level of embodied technology is normalized to 1 . We choose 1996, the last year of our data, as the numeraire year. ${ }^{20}$

\section{Discussion of variable capital utilization}

Unmeasured variation in the intensity with which plants utilize capital may lead to biases in production function estimation. We avoid this pitfall by proxying for capital utilization with energy use ${ }^{21}$. The parameter $\tau$ in the assumed functional form (11) is the elasticity of the rate of energy use with respect to capital utilization. It allows for energy use being proportional to capital services (UJ or US, as in Burnside, Eichenbaum, and Rebelo, 1995) when $\tau=1$. For values of $\tau>1$ the marginal cost of capital services increases faster with utilization than with capital stock and at the extreme $(\tau=\infty)$ there is no variation in utilization as it is too expensive. Similarly, when $\tau<1$ the marginal cost of capital services increases slower with utilization than

${ }^{19}$ We estimated some specifications allowing no time to build but assuming that investment is distributed evenly throughout the year so that, on average, six months' worth of total investment in the newest vintage is used at any one time. The estimates of $\gamma$ are uniformly higher under this specification.

${ }^{20}$ Equations (13) and (14) provide a way of aggregating vintages that embody different technology levels. Fisher (1965) shows that a necessary and sufficient condition for the existence of a capital aggregate are that the marginal rate of substitution between any pair of inputs within the aggregate be independent of the inputs outside the aggregate. Under constant returns to scale, as Solow (1960) showed, this condition requires that 1) production with each vintage be additively separable, 2) total factor productivity be the same across all vintage production functions at a given year, and 3) investment in a "better" vintage of equipment is equivalent to a larger amount" of investment measured in constant quality.

${ }^{21}$ This approach was suggested by Jorgenson and Griliches (1967) and followed by Burnside et al. (1995) for industry-level estimation and Petropoulos (1999) for plant-level estimation, among others. See Fernald and Basu (1999) for pitfalls arising from unmeasured factor utilization. 
with capital stock and at the extreme $(\tau=0)$ any variation in utilization is achieved by an infinitesimal variation in energy use. ${ }^{22}$

\section{Discussion of physical depreciation assumptions}

Our estimates of the rate of growth of embodied technological change rely importantly on accurate measures of physical depreciation. This is the part of economic depreciation that is due to wear and tear resulting from using the asset in production. We do not use the exponential depreciation rates produced by BEA, which are largely based on the estimates of Hulten and Wykoff (1981), as these reflect both physical deterioration and obsolescence. Instead, we employ the methodology used by BLS and FRB in constructing capital stocks adjusted for the effects of physical depreciation. This methodology is described in the Data Appendix.

There are two important differences. First, the FRB-BLS methodology results in an ageefficiency schedule that is vastly different from geometric, especially in the early part of an asset's life. Second, the implied rate of depreciation is much lower than that for BEA. These features can be seen in Figure 2 which graphs the average depreciation schedule by age in our primary sample for each source of depreciation data. Specifically, for the FRB-BLS depreciation data, this is the average by age (s) over all years ( $(\mathrm{t})$ and plants $(\mathrm{I})$, of the $\mathrm{D}_{\mathrm{i}, \mathrm{t}, \mathrm{-s}}$ introduced in equation $13^{23}$. The same is done for the $\mathrm{D}_{\mathrm{i}, \mathrm{t}, \mathrm{t}-\mathrm{s}}$ data that is implied by the BEA depreciation rates

according to the identity $\mathrm{D}_{\mathrm{i}, \mathrm{t}, \mathrm{t}-\mathrm{s}}=\left(1-\delta_{\mathrm{s}}^{\mathrm{BEA}}\right)^{\mathrm{t}-\mathrm{s}}$. Lastly, the depreciation schedule implied by a $12 \%$ geometric rate is provided as a frame of reference. In the empirical section, we explore the implications for our estimates of $\gamma$ of different assumptions about physical depreciation.

\section{Data}

The plant-level data we use come from the Longitudinal Research Database (LRD), which is housed at the U.S. Census Bureau's Center for Economic Studies. The LRD consists of annual data on U.S. manufacturing establishments collected in the quinqennial Census of Manufactures (CM) and the Annual Survey of Manufacturing (ASM). At this time, it covers 1963, 1967, and 1972-96. The construction of the variables that we use in our analysis is described in detail in the Data Appendix.

We construct several data samples with which to estimate equation (3). Our primary sample, which we term the "POST72A" sample, is an unbalanced panel consisting of all plantyear observations from plants born in or after 1972 that survived for at least four consecutive

\footnotetext{
${ }^{22}$ Petropoulos (1999) argues that often plants increase capital utilization by "dusting off" older, less efficient machines. Then, increases in utilization would require increasing rates of energy use per unit of capital utilized $(\tau>1)$.

${ }^{23}$ Though $\mathrm{D}_{\mathrm{i}, \mathrm{t}, \mathrm{-s}}$ has a plant subscript, this variable is the same for all plants within a 3digit industry.
} 
years (including the birth year), with the last possible observation year being 1996. Thus, a single plant may have multiple observations in our sample, provided that we continuously observe the plant's equipment investment for every year from birth until the current observation year. Observations from plants born prior to 1972 are excluded as we cannot observe their entire investment history. These missing investment variables would likely have caused substantial biases in estimating the relative efficiency of different vintages of investment.

Since we exclude plants born prior to 1972 there is a concern that our results may not be representative of the entire manufacturing sector. There is evidence (e.g. Dunne, 1991) that large, old plants invest in more technologically advanced equipment than do young, small plants. Thus, for purposes of comparison, we construct a sample containing all observations in POST72A and, in addition, plants born prior to 1972 for which we observe "most" of their investment history. Specifically, we include observations in which cumulative observed equipment investment as of the current observation year is at least $80 \%$ of the current book value of equipment assets. Assuming equipment assets are retired on a first-in-first-out (FIFO) basis, this will ensure that though capital is still understated, no more than $20 \%$ of equipment currently in place is unobserved. Again we include only observations for plants that have survived at least 4 consecutive years. We call this sample "SCREEN." 24

We keep only observations from plants that have survived at least four consecutive years in an effort to avoid two possible problems. First, the factor elasticities, particularly for capital, in the first three years of a plant's operations have been shown to be significantly different than those in later years (see Bahk and Gort (1993)). In fact, the elasticity of output with respect to capital is often found to be statistically insignificant in the first few years. Bahk and Gort attribute this phenomenon to learning by doing. Second, data is imputed for a substantial portion of any given year's newly-born plants (with the exception of data on industry, employment, and payroll). Thus, data from the first year of plants is fraught with measurement error. Since we utilize the entire investment history of a plant, we are not immune to the measurement error introduced by imputation of the first year's equipment investment. However, the share of investment that is imputed becomes smaller and smaller as the plant ages and thus, it is hoped, its impact should be minimal by the fourth year.

There is a trade-off between the improved data reliability, achieved by excluding observations from the first three years of a plant's operations, and the potential introduction of a sample selection bias by only selecting observations that were "successful" enough to survive at least four years. To ensure that our results are not unduly affected by this type of bias, we also create a sample, called POST72B, which is a superset of POST72A and relaxes the restriction that plants survive at least four years. Due to the imputation of data for the first year of many plants, we still exclude observations from the birth year. This should almost entirely eliminate the possibility of a "survivorship" bias in the regressions run using this sample since plants are allowed to exit after their second year.

${ }^{24}$ The $80 \%$ cut-off value was chosen based on an analysis of the cross-sectional distribution of the ratio of cumulative observed investment to current book value for each year in the LRD. This screen/cut-off applies to plant-year observations, that is earlier observations for a plant may be screened out while later ones may be kept. 
For a final alternative to our primary sample (POST72A), we also construct a balanced panel sample consisting of 1975-96 observations from plants that were continuously in the LRD from 1972-96 (but not necessarily born between 1972-96). This was done in order to facilitate comparison to the rest of the literature on plant behavior since similar balanced panels are frequently used. Following our previous discussion, we expect the 1972-96 panel to suffer greatly from problems of omitted variables bias (due to unobserved pre-1972 investment) and sample selection bias.

\section{Is our Sample Representative of Manufacturing?}

The POST72A sample seems to be the best alternative when trying to jointly minimize the potential biases discussed above. It consists of a total of 96,846 plant-year observations covering 24,404 plants. The Data Appendix provides detailed comparison of POST72A to the other data sets we use and to the aggregate manufacturing sector (according to published Census data). In terms of the dynamic behavior of its plants, this sample is quite representative of the manufacturing sector as a whole. The average growth rates of investment and employment are quite similar over the 1975-96 period. This is true even though the sample, due to the nature of the LRD, consists of plants that are larger, on average, than the typical manufacturing plant (in terms of gross shipments, employment, or investment) as aggregate activity is primarily shaped by large plants. The sample distribution of shipments across 2-digit SIC industries is also quite representative of manufacturing though there is a tendency to under-represent mature-plant industries such as Petroleum and over-represent young-plant industries such as Communications.

\section{Results}

In this section we present the results of our estimation. We employ non-linear least squares (NLLS) with a heteroskedasticity- and autocorrelation-consistent (HAC) variancecovariance matrix. The HAC VC matrix is necessary because autocorrelation of the errors is likely due to the fact that the same plant can have multiple observations in our sample. All regressions include year and industry dummies as well as industry-specific time trends. In addition, we include a dummy variable, which we call Multi, indicating whether the plant is part of a firm that operates multiple plants. Table 1 contains our main results.

Initially, we do not allow for variable capital utilization by setting $\tau=\infty$. As may be seen in column (A), the rate of growth of embodied technological change, $\gamma$, is estimated to be a little under 8 percent. This is higher than the rate calculated in the price-based approaches using Gordon's (1990) data. The coefficient on Multi indicates that plants in a multi-establishment firm have on average 8.7 percent higher TFP than single-establishment firms, other things equal. This is consistent with past results in the plant-level literature (see, e.g., Baily, Hulten, and Campbell (1992)). The estimated factor elasticities are quite close to observed factor shares with 
the exception of the capital coefficients, which are a bit lower. ${ }^{25}$

The data seem to support allowing for variable capital utilization, at least as proxied by energy use. As may be seen in Column (B), the estimate of $\tau$ is 2.08 (with a standard error of 0.09). This value implies that the marginal cost of capital services (UJ or US) increases faster with utilization than with capital stock. In particular the Leontief assumption employed by Jorgenson and Griliches (1967) and Burnside et al. (1995), $\tau=1$, is rejected by our data. The estimated elasticities of capital and labor change in the direction one would expect if plants vary their capital utilization significantly in response to shocks. Not taking such variation into account creates an omitted variable likely to be positively correlated with employment (biasing its coefficient upward) and negatively correlated with the stock of capital (biasing its coefficient downward $)^{26}$.

As may be seen in (B) controlling for variation in utilization reduces the coefficient of labor by 2 percent while it increases the sum of the coefficients of capital by more than a third bringing the ratio of the elasticities of labor and capital to about 2 to 1 , as expected. Returns to scale are estimated to be 0.98 which is not statistically significantly different from one. The estimate of $\gamma$ is much higher now at 17 percent. This implies a vastly higher rate of embodied technological change than is usually considered.

\section{Learning Effects}

Several papers since Arrow (1962) have suggested that the installation of new equipment embodying improved technology may involve significant subsequent investments in training workers as well as experimentation in the organization of production. These would tend to reduce productivity initially while raising it eventually and Arrow (1962) termed this process "learning by doing". ${ }^{27}$ Ignoring such learning effects might bias our estimate of $\gamma$, though the direction of the bias is not clear. To explore the extent of such problems we repeat our estimation including an indicator of whether the plant undertook an equipment-investment spike together with seven lags of it. ${ }^{28}$ Our idea is that spikes are associated with most instances of an

${ }^{25}$ Allowing factor elasticities to vary by industry yields a slightly lower estimate of $\gamma$ of 0.055 (0.028). However, many of the estimated elasticities are nonsensical, particularly those for structures. It appears allowing industry-varying elasticities may be asking too much from the data and therefore we maintain the assumption of common elasticities for the regressions to follow.

${ }^{26}$ For plant-level evidence on these patterns of correlation see Sakellaris (2000).

${ }^{27}$ See Greenwood and Jovanovic (1998) for an extensive analysis of the macroeconomic implications of learning-by-doing as well as references to some recent work.

${ }^{28}$ We identify a spike with observations of equipment investment to capital ratios greater than 0.20. See Power (1998), Doms and Dunne (1998), Cooper et al. (1999) and Sakellaris (2000) for justification of using this definition at the plant level. 
introduction of a new and "better" vintage of technology and the inclusion of the spike indicators should control for learning effects on productivity. As may be seen in column C of Table 1, the estimate of $\gamma$ is about 12 percent and the rest of the coefficients do not change much. ${ }^{29}$

\section{Average Vintage Effect}

In Section 3 we mentioned that an alternative production-based approach which obtains $\gamma$ via the estimated coefficient on average age or vintage is due to Nelson (1964). In the most parsimonious case where one does not allow for unobserved utilization or learning effects, this approach leads to the following specification (ignoring the constant, the error term, and time and industry dummies):

$$
\mathrm{y}_{\mathrm{it}}=\rho \cdot \mathrm{t}+\beta \cdot 1_{\mathrm{it}}+\theta \cdot \mathrm{m}_{\mathrm{it}}+\eta \cdot \mathrm{s}_{\mathrm{it}}+\alpha \cdot \mathrm{j}_{\mathrm{it}}^{\prime}+\alpha \cdot \log \left(1+\gamma \overline{\mathrm{V}}_{\mathrm{it}}\right)
$$

where $\mathrm{j}^{\prime}$ is log equipment capital unadjusted for embodied technological change (i.e. $\mathrm{j}^{\prime}$ is just $\mathrm{j}$ from equation 14 with $\gamma$ set equal to zero) and $\bar{V}$ is the average vintage of equipment for plant I in year t. Generally, $\gamma \overline{\mathrm{V}}$ is assumed to be close to zero allowing the last term in (15) to be approximated by $\alpha \gamma \bar{V}_{\text {it }}$. In our sample, however, the mean (over all plant-year observations) average vintage is approximately 12 (corresponding to 1984). The product of 12 and even a very small $\gamma$, say 0.01 , will still be far from zero suggesting that serious specification errors are likely when we estimate (15).

In fact, as shown in column (D) of Table 1, the Nelson method yields the rather implausible estimate of 27 percent for $\gamma$ which is significantly different from the 12 percent found using our method.

\section{Industry-specific time trends}

We are concerned that dynamic behavior of output, inputs, and disembodied technological change may differ substantially across industries. A prominent example is the computer sector which has enjoyed rapid growth in its productivity relative to other manufacturing industries and a correspondingly rapid relative decline in its price index. In order to control for this we include a set of industry-specific time trends in each of our regressions. All industry trends were between \pm 1 percent with the important exceptions of computers $(8.3 \%)$ and communication equipment (3.3\%). ${ }^{30}$ Given that the computer industry has such a high rate of

\footnotetext{
${ }^{29}$ The coefficients on the spike indicators show an approximately $6 \%$ drop in productivity in the first year after a spike with slow recovery thereafter.

${ }^{30}$ These estimates refer to the regression in Column C though the corresponding estimates from the other regressions are quite similar. We were able to reject the hypothesis that industries do have a common time trend via a Wald test at a $99 \%$ level of confidence. The F-statistic is
} 
disembodied technological change, it is natural to wonder whether the computer industry is the primary driver of our high estimates of $\gamma$. Omitting the computer industry decreases our estimate from 0.116 to 0.070 (with a std. error of 0.053 ). Thus, it appears the computer industry is $a$ but probably not the primary driver of economy-wide embodied technology.

\section{Alternative Depreciation Assumptions}

The estimate of $\gamma$ depends crucially on our assumption for physical depreciation. We now explore the implications of alternative assumptions on depreciation. We go through two hypotheses that imply that current methods of capital stock construction are valid. Our departure point is the observation that the PCE deflator and the official equipment-investment price index do not display very different trends for manufacturing (see Figure 1).

The first hypothesis is that: a) there is no embodied technological change and as a result PCE and official equipment-investment deflators are correctly measured and roughly similar over the 25-year period studied here, and $b$ ) the BEA geometric rates are accurate measures of physical depreciation alone (despite the fact they differ greatly from the FRB patterns of physical depreciation). Hypothesis 2 is that: a) there is embodied technological change, b) whereas the consumption goods price is correctly measured by the PCE deflator, the official equipmentinvestment deflator does not adjust at all for embodied technological change, and c) the BEA geometric rates correctly measure the combined effect of physical depreciation and obsolescence.

Unfortunately, the above two hypotheses are observationally equivalent with our data and methodology. To evaluate whether either could be true we perform two experiments, the results of which are shown in Table 2. In columns $\mathrm{A}$ and $\mathrm{C}$ we impose the BEA rates in place of the schedules for $D_{t, t-s}$ obtained with the BLS-FRB methodology. An alternative check is to impose zero depreciation and see whether the estimate of $\gamma$ is approximately equal to the average BEA rate for our sample, $12 \%$. The results of this are shown in Columns B and D. Columns A and B correspond to the baseline specification which does not control for variable capital utilization or learning effects, whereas Columns $\mathrm{C}$ and $\mathrm{D}$ corresponds to our preferred specification which does control for these effects. When BEA rates are used, the estimates of $\gamma$ are insignificantly different from zero providing support for these hypotheses. The estimates in Columns B and D, however, are inconsistent with either of the hypotheses. In our preferred specification the estimate of $\gamma$ is 24.5 percent with a standard error of 6.5 percent, which is statistically different from 12.1 at the $10 \%$ level of significance. The evidence is less contradictory to these hypotheses in the baseline specification that does not control for variable capital utilization. Thus, the strength with which we can reject these hypotheses depends upon which specification one prefers. ${ }^{31}$

Next, we entertain the possibility that physical depreciation rates are near-geometric and amount to various fractions of the BEA rates. We construct the parameterized capital stock using

84.5 , far greater than the $99 \%$ critical value of 1.8 .

${ }^{31}$ Deflating by the equipment-investment deflator instead of the PCE deflator does not change our conclusions. 
as physical depreciation rates some fraction times the BEA-provided rate for each observation's industry and year. We then estimate how $\gamma$ varies. Table 3 and Figure 3 contain the results. As expected, the lower is the assumed depreciation rate the higher is the estimate of $\gamma$, which ranges from 0 to 25 percent (with a standard error of approximately 6 percent). Clearly as we allow less and less of the decrease in productivity of early vintages of investment over time to be explained by physical decay, $\gamma$ is left to explain, rightly or wrongly, more of this decrease. Total economic depreciation, the sum of physical decay and obsolescence, ranges from 13 to 25 percent. Also shown in Figure 3 is the average BEA economic depreciation rate of $12 \%$ and the implied rates of obsolescence as the physical depreciation rate is increased. Our estimated $\gamma$ 's and implied economic depreciation rates differ from those suggested by the BEA data in two important respects. First, except when physical depreciation is assumed $100 \%$ of the BEA rates, our $\gamma$ 's and economic depreciation rates are substantially higher (though not statistically so). Second, the $\gamma$ 's exhibit a steepening rather than constant slope as assumed physical depreciation increases. This suggests that the assumption of near-geometric physical depreciation rates may be inappropriate.

\section{Estimates from Cross-sections}

It is impossible to decompose productivity change into its embodied and disembodied components by using time series data for a single plant, firm, industry, or economy (see Hall 1968 for a discussion of this identification problem). The basic insight of this paper is that, armed with data on physical depreciation, one can isolate the embodied component by exploiting the large cross-sectional variation in investment histories within a given year that is available at the plant-level. In principle, we could estimate our model (equation 10) using only one crosssection. However, we pooled many cross-sections in order to maximize the number of observations (and therefore the variation in investment distributions). Naturally, one may ask whether similar estimates of $\gamma$ may be obtained with the cross-sections alone.

Table 4 shows the results of such an exercise using cross-sections from 1980-96 of our primary sample. The top portion of the table involves a specification in which unobserved utilization is controlled for (as in Column $\mathrm{C}$ of Table 1). It is clear from the large standard errors here that pooling the cross-sections is vital to obtaining any reasonable precision on $\gamma$. The median estimate, mean estimate, and standard error of the mean are $0.239,0.216$, and 0.046 , respectively.

Despite the large standard errors, one may wonder if the large variation in $\gamma$ across crosssections indicates that the true $\gamma$ has varied greatly over time. To test this, we estimate our full specification on the pooled sample allowing $\gamma$ to vary by year and test the hypothesis that $\gamma$ is constant. The F-statistic for this test is 0.17 compared to a $95 \%$ critical value of 1.00 . Thus, one cannot reject the hypothesis of a constant $\gamma$ over cross-sectional years.

The cross-sectional results in Table 4 are also helpful in assessing whether our pooled estimate of $\gamma$ is affected by the assumption that the elasticity of energy usage with respect to capital utilization, $\tau$, is constant. It is possible that $\tau$ was lower in the 1970 's when energy costs were high than it was in the 1980's and 1990's. It can easily be shown that the contribution of equipment capital to output, $\alpha(\tau-1) / \tau$, is increasing in $\tau$. If the constant average, and estimated, $\tau$ 
is higher (lower) than the true $\tau$ for early (later) vintages, then the contribution of early vintage equipment to output would be overstated (understated). To compensate, the estimation procedure in its efforts to minimize the sum of squared errors will want to underweight early vintage investment relative to later investment as it searches for the SSE-minimizing $\hat{\gamma}$. This implies an upward bias in $\hat{\gamma}$. This is a possible explanation for the increase from $8 \%$ to $17 \%$ when we adjust for utilization (see Columns A and B of Table 1).

However, our cross-sectional results provide strong evidence that this is not the case. In the cross-sections, $\tau$, like all other parameters, is estimated separately for each year. The bottom portion of Table 4 refers to the specification that does not control for unobserved capital utilization (same as in Column A of Table 1). If the 9\% difference we get in the pooled regressions is due to an unaccounted-for trend in $\tau$, then this difference should disappear in the cross sections. In fact, on average, this difference is slightly higher (though not significantly so) at about $10 \%$ for any particular cross-section.

Furthermore, allowing only $\tau$ to vary by year and estimating our full specification over the pooled sample yields a gamma of 0.127 (0.054) compared to the $0.116(0.060)$ in Table 1, Column C. $\tau_{t}$ does in fact exhibit a slight rising trend over time which is statistically significant according to a Wald test. ${ }^{32}$

\section{Results from other Samples}

As mentioned in Section 5, our primary sample, POST72A, was chosen so as to minimize the possible effect of several biases. We now present results using other samples. ${ }^{33}$ POST72B was created in order to evaluate the likelihood of a "survivorship" bias. There is a possible sample selection bias introduced by the fact that unproductive plants are unlikely to survive for many consecutive years and our primary sample excludes plants that have not survived for at least 4 years. ${ }^{34}$ Plants with high expected present discounted values of future profits may be more likely to invest in high-tech equipment than plants with less rosy prospects for the future. These plants are also more likely to survive for a long period. Moreover, investing in high levels of embodied technology is likely to be a cause of future profitability and survival ${ }^{35}$. Therefore, plants with higher than average shares of vintage investment in high-tech equipment in the early

\footnotetext{
${ }^{32}$ The F-statistic for the test of the null hypothesis that $\tau$ is constant for all years is $8.48>\mathrm{F}_{\mathrm{J}, \mathrm{T}-\mathrm{K}}(.95)=1.00$.

${ }^{33}$ Section 5 describes the various samples and discusses the potential biases that are involved.
}

${ }^{34}$ Evidence for this may be found in Baily, Hulten, and Campbell (1992), and Olley \& Pakes (1996), among others.

${ }^{35}$ This intuition is confirmed in a study by Timothy Dunne (1991) who analyzes plantlevel data from the Survey of Manufacturing Technology. He shows that large, old plants utilize new technologies more intensively than young, small plants. 
years of the sample are more likely to be included in POST72A. Having higher than average (relative to the average manufacturing plant in a given year) levels of embodied technology in the early years of the sample should result in a downward bias in $\gamma$. However, our results show that $\hat{\gamma}$ is actually higher (though not significantly so) with our primary sample compared to that with POST72B, which seems to indicate that this potential source of bias is not a serious concern. This can be seen in Table 5 which displays the results from estimating our full specification using each of our four samples. ${ }^{36}$

The SCREEN sample is an effort to increase the sample size and representativeness by including observations from plants which have a small amount (less than $20 \%$ of current equipment assets) of unobserved pre-1972 investment. However, because pre-1972 investment is omitted and no variable is available to proxy for it, this introduces an omitted variable bias, the direction of which depends on the correlation between pre-1972 and post-1972 equipment investment. In a model of lumpy investment, the larger a plant's current effective capital stock, the less likely the plant is to invest in new capital, implying a negative correlation. ${ }^{37}$ This implies a negative bias on $\alpha$. Evaluating the likely bias on $\gamma$ is more complicated. The correlation between pre- and post-1972 investment should be more negative for early post-1972 investment since as time goes on the pre-1972 equipment is gradually retired and therefore no longer contributes to production (and hence does not factor into contemporaneous investment decisions). Thus, the omitted pre-1972 equipment causes one to underestimate the contribution of early vintages relative to later vintages. This implies a positive bias on $\gamma$.

These priors are in fact supported by the data. The estimate of $\alpha$ falls from 0.114 with POST72A to 0.099 with SCREEN, while $\hat{\gamma}$ rises from 0.116 to 0.209 .

Finally, because balanced panels are commonly used in plant-level studies, we also created a sample consisting only of plants that were continuously observed from 1972 to 1996. This sample is also affected by the omission of pre-1972 investment and is likely to be strongly affected by a survivorship bias as well. Though we found no evidence of a survivorship bias in our primary sample where plants could not exit until after 4 years, a survivorship bias seems far more likely in this balanced panel of 25 years. The $\hat{\gamma}$ obtained using this sample is 0.039 . Though it is possible that large, old, and successful plants have a lower true rate of embodied technological change, it seems more plausible that this lower $\hat{\gamma}$ is evidence of a serious survivorship bias.

Simultaneity Bias

${ }^{36}$ For estimations using the POST72B sample, we include a dummy variable indicating whether or not the plant was born in the previous year together with two lags of this. The coefficients on these variables indicate that all else equal, productivity is $2.5 \%$ below average in the first year after a plant's birth, $2.1 \%$ below two years after, and $1.7 \%$ below three years after.

${ }^{37}$ This intuition is supported by Cooper, Haltiwanger, and Power (1999) who find that the probability of investment in a given year increases with the time since the plant's last large investment. 
It is well known that OLS estimation of production function relationships is subject to potential simultaneity biases ${ }^{38}$. Since the "independent" variables are production inputs that are chosen optimally by the producers, the usual exogeneity assumptions that are required for the consistency of OLS may fail. A plant manager's input choices are determined by plant quality (or, equivalently, managerial efficiency, or disembodied technology) along with factor prices and product demand. Since part of this quality is unobserved by the econometrician, it is subsumed into the disturbance term of the production function. The result is that variable inputs may be correlated with the disturbance term.

To address the possibility of simultaneity bias, we attempted a non-linear instrumental variables (NLIV) estimation. An appropriate set of instrumental variables should include all exogenous variables in the model together with other exogenous and relevant (i.e. correlated with the Jacobian vector of first derivatives of the model with respect to the parameter vector) instruments. For identification it is necessary to have at least one instrument per parameter to be estimated. Unfortunately, it is very difficult to find good instruments (exogenous and relevant) at the plant level for our purposes. This limits severely the success of our NLIV estimations as we will see below. In order to address these problems partially, we try to minimize the number of parameters to be estimated by following a suggestion of Griliches and Ringstad (1971). We replace factor elasticities of some or all of the inputs (e.g. of materials and labor) with measures of their share in cost (using 4-digit industry-level data from the NBER-CES Productivity Database and 2-digit equipment and structures rental rates from the BLS). This leaves in some cases $\gamma$, and $\tau$ as the only parameters to be estimated.

For instruments, we use the set of 4-digit industry-level downstream demand indicators originally constructed by Bartelsman, Caballero, and Lyons (1994) and modified by Baily, Bartelsman, and Haltiwanger (1996). An industry's demand indicator is a weighted average of the economic activity of manufacturing and service industries (downstream industries) that purchase the industry's output. The weights are the share of each downstream industry's purchases in the upstream industry's total output and the measure of economic activity is the sum of the cost-share weighted growth rates of each factor input (capital, labor, and materials). In order to filter out any endogenous effect that an upstream industry's productivity may have, through its output price, on downstream industries' activity, the indicator excludes the activity of downstream industries whose purchases from the upstream industry are greater than 5\% of their total intermediate input purchases. The instrument set also includes the second through fourth powers of this downstream demand indicator, and investment lagged 3 through 24 years (24 is oldest possible non-zero lagged investment that a plant in our sample can possibly have). ${ }^{39}$

${ }^{38}$ Marschak and Andrews (1944) were the first to recognize this problem. Griliches and Mairesse (1995) provide a thorough discussion of the issue together with attempts to ameliorate the problem using plant-level data.

${ }^{39}$ It may be argued that past investment, even lagged more than three years, is endogenous. Unfortunately, when we omit lagged investment from our set of instruments, our first-stage $\mathrm{R}^{2}$ drops substantially and the standard errors rise making the estimates essentially meaningless. 
The results of these regressions are shown in table 6. Column A shows the regression results from our preferred specification where labor's and material's elasticities are not estimated but rather are measured by their industry cost shares. Column B shows the results from the same regression except that all factor elasticities are measured by their industry cost shares and no utilization adjustment is made. ${ }^{40}$ Column $\mathrm{C}$ contains results from an average vintage specification also without a utilization adjustment and with all factor elasticities measured by cost shares.

The results of our IV estimations are inconclusive. Largely due to the inclusion of lagged investment in our instrument set, our first-stage $\mathrm{R}^{2} \mathrm{~s}$ (not shown) are fairly high, particularly for the first derivative of $\gamma$. Yet, despite this apparent relevance, we are not able to estimate $\gamma$ with any reasonable degree of precision. Of the three regressions shown, only the estimate of $\gamma$ in column B is significant. Based on unreported OLS results we conclude that the negativity of $\hat{\gamma}$ is most likely due to the imposition of the industry cost-shares rather than to the use of IV. In summary, despite our efforts to instrument for endogeneity, we are not able to rule out the possibility of simultaneity bias in our estimate of $\gamma$.

\section{Why do we not use the Olley and Pakes (1996) method?}

Olley and Pakes (1996) present a model of plant behavior that motivates a three-stage algorithm for estimating a production function while controlling for factor endogeneity and selection bias due to endogenous exit. The model relies crucially on an "invertibility condition." This amounts to investment being a monotonic function of unobserved productivity, and observed plant state variables such as capital stock. This allows productivity to be expressed as an inverse function of investment and these state variables.

In the first two stages of the Olley-Pakes algorithm, output is projected on the variable inputs and a polynomial function, which proxies for unobserved productivity, in terms of investment and the plant-specific state variables (capital and age in their model). The probability of survival is then estimated as a similar polynomial. In the third and final stage, the estimated values of the contribution to production from variable factors and productivity, and the endogenous effects of survival, from the first stage, are subtracted from output and the remainder is regressed on the plant-specific state variables in order to estimate their contributions to production. For our study, the second stage of their method would not be necessary since our data sample allows for most entry and exit and thus largely eliminates the possibility of selection bias from only observing plants that survive for the length of the panel.

Why not then apply the Olley-Pakes approach to our model which allows for the embodied technological change? The problem is that capital stock is not an observed plant state variable in our approach. We use a parameterized stream of current and past investment rather than a capital stock construct. This renders unidentifiable the separate effects of embodied technology in current investment and the productivity signal of current investment.

\footnotetext{
${ }^{40}$ The iterative estimation procedure was not able to converge when $\tau$ was included in the regression.
} 


\section{Productivity growth decomposition}

Our findings have the important implication that the equipment capital stock is mismeasured considerably in studies of productivity growth or production function estimation. In particular, we estimate that the stock of equipment grows at much faster rates than is reflected in conventional methods. As may be seen in Table 7, the growth rate of equipment capital stocks depends crucially on the assumptions made on physical depreciation, the investment-price deflator, and the rate of growth of embodied technological change. ${ }^{41}$ We calculate the annual growth rate of equipment capital stock under five different sets of assumptions. ${ }^{42}$ The growth rate of the stock implied by the results from our main regression (Column $\mathrm{C}$ of Table 1), with $\gamma=0.116$, is 14.7 percent. This is substantially higher than the growth rate of the conventional capital stock $(\gamma=0$, investment deflated by the FRB/PPI investment deflators and adjusted for depreciation using the BEA/Hulten-Wykoff rates), which is 4.2 percent in our sample. It is also far above the growth rates of the capital stocks endorsed by either Hulten (1992) or Greenwood, et al. (1997), which are both 7.0 percent in our sample. The key element that generates the higher growth rate in our capital stock construct is the value of $\gamma$. When we set $\gamma$ to zero but use the FRB/BLS depreciation data and the PCE deflator to construct the capital stock its growth rate is only 4.4 percent.

We now examine the relative importance of embodied and disembodied technological change for productivity growth in our sample of U.S. manufacturing plants. According to equation (3), the residual growth rate in output, after accounting for quality-adjusted input growth, is due to technological change that is not embodied in equipment investment. That growth rate in our sample is 0.57 percent annually. ${ }^{43}$ Correspondingly, the rate of output growth that is due to embodied technological change is equal to the equipment elasticity times the differential growth rate of quality-adjusted and non-quality adjusted equipment capital stocks. This measure averages 1.17 percent annually in our sample. ${ }^{44}$ The implication is that equipment-

\footnotetext{
${ }^{41}$ For the construction of these capital stocks, a numeraire year $\left(\mathrm{t}_{0}\right)$ of 1972 was used. The choice of numeraire year can affect whether the growth rate of capital is monotonically increasing or monotonically decreasing in $\gamma$. This can be seen easily by taking the derivative of $\left(\mathrm{J}_{t} / \mathrm{J}_{\mathrm{t}-1}\right)$ with respect to gamma where $\mathrm{J}_{\mathrm{t}}$ is defined according to equation (14). Choosing a numeraire year at the beginning of our sample ensures that the growth rate will increase with $\gamma$. What is important for comparing capital stock growth rates using different $\gamma$ 's is not necessarily the sign of this derivative, but just that the derivative is monotonic in $\gamma$.

${ }^{42}$ Specifically, we regress the log of equipment capital stock on $t$ and an intercept. The coefficient on year gives the average annual growth rate.

${ }^{43}$ This number comes from the coefficient on $t$ after regressing the log of TFP, constructed using the equipment capital stock with a $\gamma=.116$, on $t$ and an intercept.

${ }^{44}$ The equipment elasticity is 0.114 from Column $\mathrm{C}$ of Table 1 . The approximate annual growth rate in the equipment capital stock due to embodied technological change is 10.3 percent.
} 
embodied technological change accounted for about two-thirds of total technological change between 1972 and 1996 in our sample of U.S. manufacturing plants.

\section{Conclusion}

Determining the rate of embodied technological change is of crucial importance. It is a necessary ingredient for productivity analysis which relies on accurate measures of capital accumulation. Furthermore, it tells us how much of the decline in an asset's value as it ages can be attributed to obsolescence.

In this paper, we develop a production-side approach that can provide alternative estimates of embodied technological change to price-based estimates. We find that the rate of embodied technological change is between 8 and 17 percent. These rates are much higher than that suggested by the relative rate of decline of Gordon's (1990) equipment price deflators which puts it no higher than 4\%. These results are consistent with arguments made by Hornstein and Krusell (1996), Gort and Wall (1998), and others who argue that these price-based estimates are likely to understate true embodied technological change.

If our estimates are accurate, embodied technological change may account for as much as two-thirds of the total growth in TFP, suggesting an important role for investment in spuring productivity growth above and beyond the traditional role of capital deepening.

This number comes from subtracting the 14.7 percent in Row A of Table 7 from the 4.4 percent in Row B. 


\section{Data Appendix - Variable Construction and Sample Characteristics}

\section{Variable Construction}

Each of the data samples described in Section 5 contain the same variables. The definitions of gross output, labor, structures capital stock, materials, and energy are similar to those used in the plant-level literature (see Dunne 2000). The Real gross output was defined as value of shipments plus inventory change deflated by the 4-digit SIC shipments deflator in the NBER-CES data base (see Bartelsman and Gray 1996). The concept of "production-worker equivalent hours" was used for the labor variable:

$$
L=p h+(n w / p w) p h,
$$

where ph is production worker hours, $\mathrm{nw}$ is total nonproduction worker salaries and wages, and pw is total production worker salaries and wages. Assuming workers are paid their marginal product, the second term should capture "production worker equivalent hours" contributed by nonproduction workers. Real energy expenditures is measured as the sum of the costs of fuel and electricity deflated by the NBER-CES energy deflator. Real materials is the sum of the costs of fuel, electricity, and parts, deflated by the NBER-CES materials deflator.

The structures capital stock is defined according to the tradition perpetual inventory definition:

$$
S_{t}=\sum_{j=1}^{T} I_{t-j}^{S} D_{t, t-j},
$$

where $\mathrm{T}$ is the age of the plant, $\mathrm{I}^{\mathrm{S}}$ is new structures investment (deflated using 3-digit structures investment deflators from the FRB), and $D_{t, t-j}$ is the fraction of structures investment of vintage t-j that remains productive in year $t$. We describe below the construction of these age-efficiency profiles for structures and equipment, $\mathrm{D}_{\mathrm{t}, \mathrm{t}-\mathrm{j}}$, for each 3-digit SIC industry.

\section{Physical Depreciation Measures}

We employ the methodology used by BLS and FRB in constructing capital stocks adjusted for the effects of physical depreciation (for details see Mohr \& Gilbert 1996). For each vintage of investment we repeat the following procedure. First, the industry-level capital expenditures are split among 35 asset categories. This is accomplished with an iterative matrix balancing (RAS) technique that employs the industry-level investment data as column controls and utilizes (aggregate-economy) NIPA data on asset-level capital expenditures as row controls for the 35 asset categories. Data derived from BEA's Capital Flows Tables (CFT) provide initial asset-by-industry investment shares for the iterative procedure.

Second, these asset expenditures by industry are transformed from a current-dollar to a constant-dollar basis to obtain estimates of real investment by asset type that can be compared 
across time. All assets are deflated using the PCE deflator. Third, we use mean service lives that are specific to each asset type and adjusted to account for expected retirements from each asset-type investment bundle around its mean life. These mean service lives were supplied by BEA except for autos. A discard density function captures stochastic retirements around these mean lives, whereas a hyperbolic- (or beta-) decay function captures the effect of physical deterioration due to wear and tear. We adjust real industry investment by asset type for the joint effects of the decay and discard processes rather than just the latter. In effect, we create a series for each asset of the amount of the vintage that will still be productive at age $a$. Finally, we aggregate all assets of the same vintage to derive age-efficiency schedules specific to vintage and investing-industry.

The BLS-FRB methodology has two important results. First, the age-efficiency schedule is vastly different from geometric, especially in the early part of an asset's life. Second, the implied rate of physical depreciation is much lower than the economic depreciation rates produced by the BEA.

\section{Sample Characteristics}

The special characteristics of the LRD, from which the overall data set was drawn, combined with the need to have continuous investment histories, necessitate a thorough analysis of the properties of each of the samples we use. Figures 4-16 illustrate some of these properties.

The LRD contains data from the Census of Manufacturers (CM) and the Annual Survey of Manufactures (ASM). The CM is conducted every five years in years ending in " 2 " and "7". It collects data on approximately 300,000-380,000 plants. The ASM is based on a panel of plants which are sampled from the CM universe and followed for 5 years. Within the 5-year interval of an ASM panel, the Census Bureau also adds to the panel a sample of plant births for each year. A new ASM panel is selected at the beginning of the second year after a CM. Thus, the 6 ASM panels in the current LRD are 1972-73, 1974-78, 1979-83, 1984-88, 1989-93, and 1994-96. Plants are selected for the ASM based on their size and their share of industry output. Plants with more than 250 employees are sampled with certainty while smaller plants are sampled with probabilities proportional to their size.

Figure 4 shows, for each year from 1975-96 and on average, the fraction of all U.S. manufacturing plants that are accounted for by each sample. The timing of ASM panel selection has a clear effect on the annual sample size of POST72A, POST72B, and SCREEN. There are substantial drops in sample size in the first year of each ASM panel $(1979,1984,1989$, and 1994). This can be attributed to the reselection of the ASM panel in these years which eliminates many plants from the LRD, though these plants do not necessarily cease operations. Averaged over the sample period, our primary sample, POST72A, is the smallest at $1.2 \%$ of manufacturing. ${ }^{45}$ Including observations from plants that are observed for only two or three consecutive years (as in POST72B), we reach an average of roughly $2 \%$. The fact that the plants in the 1972-96 panel, nearly all of which were born prior to 1972, generally account for more of

${ }^{45}$ Over the 1975-96 period, there was an average of roughly 365,000 manufacturing plants with an average of 4402 of them in the POST72A sample. 
total manufacturing than those of POST72B shows that we sacrifice a great number of observations in order to avoid having unobserved pre-1972 investment. The SCREEN sample is able to keep many of these observations, in addition to including plants born after 1972 that survive for at least four consecutive years. Thus, it is not surprising that the SCREEN sample is the largest on average at approximately $2.8 \%$ of manufacturing.

Despite the relatively small fraction of all manufacturing plants accounted for by these samples, they represent a much higher share of manufacturing in terms of gross output (shipments), employment, and investment. This is demonstrated for shipments in Figure $5 .{ }^{46}$ As plants born prior to 1972 exit or shrink and plants born after 1972 enter and expand, the post1972 samples, POST72A and POST72B, account for increasingly larger shares of manufacturing, reaching $13.4 \%$ of the total value of shipments by 1996. The expansion of post-1972 plants is also evident in the mean shipments, employment, and investment for plants in each sample (and for total manufacturing). Mean shipments by year is shown in Figures 6. Again, the employment and investment graphs (not shown) tell a similar story. One can see a general rise over the 197596 period for each sample as well as for overall manufacturing. With the exception of the 197296 panel, the samples display a marked jump in mean activity in the beginning year of each ASM panel $(1979,84,89$, and 94). This is due to the fact that, for the most part, only large plants (having over 250 employees) are selected to consecutive ASM panels. Thus, smaller plants which were probabilistically selected for one ASM panel are unlikely to be selected for the next panel. As all plants, and particularly those that stay in the ASM from one panel to the next, grow over time, the mean activity of plants in POST72A, POST72B, and SCREEN jumps at the start of each ASM panel.

The above effects also influence the average age, which is shown in Figure 7. For plants born after 1972, age is simply the number of years since birth. For plants born during or prior to 1972, I make use of data from the 1975 and 1981 CM's which asked establishments to report the year they began operations. This birth year data was compiled by Davis, Haltiwanger, and Schuh (1996). As expected, the 1972-96 panel is the oldest sample followed by Screen, POST72A, and POST72B. Quite mechanically, the 1972-96 panel ages by exactly one year each year of the sample. The other samples, particularly POST72A and POST72B, have a flatter age profile over time, even having somewhat of a decline over the 1990's. Unfortunately, there is no way of knowing the true average age of manufacturing plants in the U.S.. However, it is likely to be lower than that of these samples (with the possible exception of POST72B) which by design tend to have plants that have survived for a substantial period of time.

Figures 8-11 show the mean (over 1975-96) distribution of shipments across 2-digit industries of each sample versus that of overall manufacturing (as reported in the NBER-CES Productivity Database). Each sample appears to be fairly representative. The over- or underrepresentation of some industries seems to be largely a function of age. For example, in our primary sample, POST72A, Petroleum (29) is substantially under-represented, while Food products (20) is over-represented. This is because Petroleum is dominated (in terms of gross output) by large, old plants whereas food products has smaller, newer plants (as well as more plants in general).

${ }^{46}$ The graphs for employment and investment look quite similar. 
Perhaps the best way to evaluate the representativeness of a sample is in terms of the dynamic behavior of its members. This is done in Figures 12 and 13, which display the growth rates of employment and gross investment for the samples and total manufacturing (published ASM). The growth rates for the samples refer to pairwise-continuous share-weighted average growth rates, in other words, the share-weighted average growth rate for year $t$ is calculated using all (and only) plants that existed in both $t$ and $t-1$. The growth rate measure used here is the symmetric and bounded "g" measure used in Davis, Haltiwanger, and Schuh (1996):

$$
g_{i t}=\frac{X_{i t}-X_{i t-1}}{\left(X_{i t}+X_{i t-1}\right) / 2}
$$

for any variable $\mathrm{X}$. The (Divisia) share-weighted average of $g$ across all pairwise-continuous plants, $\overline{\mathrm{g}}$, is calculated using the share of plant I's X in total manufacturing's X:

$$
\bar{g}_{t}=\sum_{i=1}^{N_{t}} \frac{X_{i t}}{X_{t}} \cdot g_{i t} \text { where } X_{t}=\sum_{i=1}^{N_{t}} X_{i t}
$$

The SCREEN and the 1972-96 panel samples appear to underestimate the growth in employment in the 1990's. There also appears to be an underestimation of the growth in new investment in the POST72A sample in 1976 and in the POST72B sample from 1976-81. Nevertheless, it is clear that all four samples generally track aggregate manufacturing fairly closely. 


\section{REFERENCES}

Arrow, Kenneth. "The Economic Implications of Learning by Doing." Review of Economic Studies, 29(3), June 1962, pp. 155-173.

Bahk, Byong-Hyong, and Gort, Michael. "Decomposing Learning by Doing in New Plants." Journal of Political Economy, 101(4), August 1993, pp. 561-583.

Baily, Martin; Bartelsman, Eric; and Haltiwanger, John. "Labor Productivity: Structural Change and Cyclical Dynamics.” NBER Working Paper 5503, 1996.

Bartelsman, Eric, Caballero, Ricardo, and Lyons, Richard. "Customer- and Supplier-Driven Externalities." American Economic Review, September 1994, 84(4), pp. 1075-84.

Bartelsman, Eric J., and Gray, Wayne. "The NBER Manufacturing Productivity Database." NBER Technical Working Paper 205, October 1996.

Burnside, Craig; Eichenbaum, Martin; and Rebelo, Sergio. "Capital Utilization and Returns to Scale.” In NBER Macroeconomics Annual 1995. Editors Julio J. Rotemberg and Ben S. Bernanke. Cambridge, MA: MIT Press, 1995.

Cooper, Russell; Haltiwanger, John; and Power, Laura. "Machine Replacement and the Business Cycle: Lumps and Bumps." American Economic Review, December 1999, 89(4), pp. 921-46.

Davis, Steven; Haltiwanger, John; and Schuh, Scott. Job Creation and Destruction. Cambridge, MA: MIT Press, 1996.

Doms, Mark. "Estimating Capital Efficiency Schedules Within Production Functions." Economic Inquiry, January 1996, 34 (1), pp. 78-92.

Doms, Mark, and Timothy Dunne. "Capital Adjustment Patterns in Manufacturing Plants." Center for Economic Studies Discussion Paper 94-11, August 1994.

Dunne, Timothy. "Technology Usage in U.S. Manufacturing Industries: New Evidence From the Survey of Manufacturing Technology." Center for Economic Studies Discussion Paper 91-7, October 1991.

Dunne, Timothy. "Longitudinal Research Database Technical Documentation." Mimeo, Center for Economic Studies, U.S. Census Bureau, 2000.

Fernald, John, and Basu, Susanto. "Why is Productivity Procyclical? Why Do We Care?" Board of Governors of the Federal Reserve System, IFDP no. 638, June 1999. 
Fisher, Franklin M. "Embodied Technical Change and the Existence of an Aggregate Capital Stock." Review of Economic Studies, 32, October 1965, pp. 263-88.

Gordon, Robert J. The Measurement of Durable Goods Prices. Chicago: University of Chicago Press, 1990.

Gordon, Robert J. “Can Technology Improvements Cause Productivity Slowdowns? Comment.” In NBER Macroeconomics Annual 1996. Editors Julio J. Rotemberg and Ben S. Bernanke. Cambridge, MA: MIT Press, 1996.

Gort, Michael, and Richard Wall. "Obsolescence, Input Augmentation, and Growth Accounting." European Economic Review 42, 1998, pp. 1653-65.

Greenwood, Jeremy; Hercowitz, Zvi; and Krusell, Per. "Long-Run Implications of Investment-Specific Technological Change.” American Economic Review, June 1997, 87(3), pp. 342-362.

Greenwood, Jeremy; Hercowitz, Zvi; and Krusell, Per. "The Role of Investment-specific Technological Change in the Business Cycle." European Economic Review, 44(2), April 2000, pp. 91-115.

Greenwood, Jeremy, and Jovanovic, Boyan. “Accounting for Growth.” Mimeo, June 1998.

Griliches, Zvi, and Mairesse, Jacques. "Production Functions: The Search for Identification." NBER Working Paper No. 5067, March 1995.

Griliches, Zvi, and Ringstad, V. Economies of Scale and the Form of the Production Function. Amsterdam: North-Holland, 1971.

Hall, Robert E. "Technical Change and Capital From the Point of View of the Dual." Review of Economic Studies, 35, 1968, pp. 34-46.

Hercowitz, Zvi. "The 'embodiment' hypothesis.” Journal of Monetary Economics, 41(1), February 1998, pp. 217-24.

Hornstein, Andreas, and Krusell, Per. "Can technology improvements cause productivity slowdowns?” In NBER Macroeconomics Annual 1996. Editors Julio J. Rotemberg and Ben S. Bernanke. Cambridge, MA: MIT Press, 1996.

Hulten, Charles. "Growth Accounting when Technical Change is Embodied in Capital." American Economic Review, September 1992, 82(4), pp. 964-980.

Hulten, Charles and Frank Wykoff. "The Measurement of Economic Depreciation.” 
Depreciation, Inflation, and the Taxation of Income From Capital. Editor Charles Hulten, pp. 81-125. Washington, D.C.: Urban Institute, 1981.

Johansen, Leif. "Substitution versus Fixed Proportion Coefficients in the Theory of Economic Growth.” Econometrica, April 1959, 27(2), pp. 157-176.

Jorgenson, Dale W., and Griliches, Zvi. “The Explanation of Productivity Change.” Review of Economic Studies, 1967, 34, pp. 249-83.

Marschak, Jacob, and William Andrews. "Random Simultaneous Equations and the Theory of Production." Econometrica, 1944, 12(3/4), pp. 143-205.

Mohr, Michael, and Gilbert, Charles. "Capital Stock Estimates for Manufacturing Industries: Methods and Data." Board of Governors of the Federal Reserve System, March 1996.

Nelson, Richard. "Aggregate Production Functions and Medium-Range Growth Projections." American Economic Review, September 1964, 54(5), pp. 575-606.

Olley, Steven and Pakes, Ariel. "The Dynamics of Productivity in the Telecommunications Equipment Industry.” Econometrica, 55(4), 1996, pp.1263-98.

Petropoulos, Wendy. "Industry Productivity Dynamics and Unmeasured Capacity Utilization." Mimeo, University of Michigan, November 1999.

Power, Laura. "The Missing Link: Technology, Investment, and Productivity." Review of Economics and Statistics, May 1998, 80(2), pp. 300-313.

Sakellaris, Plutarchos. "Patterns of Plant Adjustment," mimeo, University of Maryland, August 2000.

Shea, John. “Do Supply Curves Slope Up?” Quarterly Journal of Economics, 1993, 108(1), pp. $1-32$.

Solow, Robert. "Investment and Technical Progress." In Kenneth Arrow, Samuel Karlin, and Patrick Suppes, eds., Mathematical Methods in the Social Sciences. Stanford, CA: Stanford University Press, 1960, pp. 89-104. 


\section{Table 1}

\begin{tabular}{|l|l|l|l|l|}
\hline$\underline{\text { Parameter }}$ & \multicolumn{1}{c|}{$\mathrm{A}$} & \multicolumn{1}{c|}{$\mathrm{B}$} & \multicolumn{1}{c|}{$\mathrm{C}$} & \multicolumn{1}{c|}{$\mathrm{D}$} \\
\hline$\gamma$ & $0.077(0.029)$ & $0.169(0.049)$ & $0.116(0.060)$ & $0.271(0.059)$ \\
\hline Intercept & $2.298(0.049)$ & $2.421(0.054)$ & $2.369(0.080)$ & $\begin{array}{l}-1.183 \\
(1.077)\end{array}$ \\
\hline Multi & $0.087(0.008)$ & $0.079(0.008)$ & $0.080(0.008)$ & $0.080(0.005)$ \\
\hline$\beta$ & $0.344(0.005)$ & $0.322(0.005)$ & $0.319(0.005)$ & $0.318(0.002)$ \\
\hline$\Theta$ & $0.545(0.005)$ & $0.531(0.005)$ & $0.529(0.005)$ & $0.529(0.002)$ \\
\hline$\alpha$ & $0.078(0.003)$ & $0.108(0.005)$ & $0.114(0.005)$ & $0.114(0.002)$ \\
\hline$\eta$ & $0.008(0.002)$ & $0.020(0.004)$ & $0.018(0.004)$ & $0.019(0.002)$ \\
\hline$\tau$ & & $2.076(0.091)$ & $2.219(0.105)$ & $2.232(0.050)$ \\
\hline Adjusted $\mathrm{R}^{2}$ & 0.926 & 0.927 & 0.927 & 0.927 \\
\hline
\end{tabular}

A: Base regression (does not allow for capital utilization or learning-by-doing effects).

B: Adjusts for capital utilization using energy expenditures (see equation 11).

C: Full specification (adjusts for capital utilization and includes variables capturing learning-bydoing effects associated with investment spikes).

D: Average vintage regression (see equation 15).

Note: Regressions A-D also included year and industry dummy variables as well as industryspecific time trends. The coefficients on these are not shown in order to conserve space. They can be obtained from the authors upon request. 
Table 2

\begin{tabular}{|c|c|c|c|c|c|c|c|c|}
\hline$\underline{\text { Parameter }}$ & & $\mathrm{A}$ & & B & & $\mathrm{C}$ & & $\mathrm{D}$ \\
\hline$\gamma$ & 0.019 & $(0.025)$ & 0.153 & (0.029) & 0.005 & $(0.042)$ & 0.245 & $(0.065)$ \\
\hline Intercept & 2.218 & $(0.047)$ & 2.417 & (0.024) & 2.229 & (0.034) & 2.534 & $(0.081)$ \\
\hline Multi & 0.087 & $(0.008)$ & 0.086 & (0.008) & 0.080 & (0.008) & 0.080 & $(0.008)$ \\
\hline$\beta$ & 0.344 & $(0.005)$ & 0.344 & $(0.005)$ & 0.319 & $(0.005)$ & 0.319 & $(0.005)$ \\
\hline$\Theta$ & 0.545 & $(0.005)$ & 0.545 & $(0.005)$ & 0.529 & $(0.005)$ & 0.529 & $(0.005)$ \\
\hline$\alpha$ & 0.079 & $(0.003)$ & 0.079 & (0.003) & 0.115 & $(0.005)$ & 0.116 & $(0.005)$ \\
\hline$\eta$ & 0.007 & $(0.002)$ & 0.007 & $(0.002)$ & 0.017 & $(0.004)$ & 0.016 & $(0.004)$ \\
\hline$\tau$ & & & & & 2.219 & (0.106) & 2.249 & (0.109) \\
\hline Adjusted $\mathrm{R}^{2}$ & 0.926 & & 0.926 & & 0.927 & & 0.927 & \\
\hline
\end{tabular}

A: Base regression (does not allow for capital utilization or learning-by-doing effects); physical decay measured by BEA economic depreciation rates.

B: Base regression; no physical decay allowed for.

C: Full specification (adjusts for capital utilization and includes variables capturing learning-bydoing effects associated with investment spikes); physical decay measured by BEA economic depreciation rates.

D: Full specification; no physical decay allowed for.

Note: Regressions A-D include year and industry dummy variables which are not shown in order to conserve space. They can be obtained from the authors upon request. 
Table 3

\begin{tabular}{|c|c|c|}
\hline Fraction of BEA rates & Estimated $\gamma$ & $\begin{array}{c}\text { Implied Economic } \\
\text { Depreciation Rate }^{1}\end{array}$ \\
\hline 0 & $0.245(0.065)$ & 0.245 \\
\hline 0.25 & $0.205(0.064)$ & 0.236 \\
\hline 0.5 & $0.159(0.061)$ & 0.220 \\
\hline 0.75 & $0.087(0.053)$ & 0.178 \\
\hline 1 & $0.005(0.042)$ & 0.126 \\
\hline
\end{tabular}

Note: All of the estimates in column 2 were obtained using the same, preferred specification: adjustment to control for unobserved utilization and spike dummies included to control for learning-by-doing effects (i.e., the same specification as was used in Table 1, Column C).

${ }^{1}($ Column 1$) *($ Average BEA depreciation rate $=0.121)+($ Column 2$)$. 


\section{Table 4}

\begin{tabular}{|c|c|c|c|c|}
\hline Gamma & Std. error & Adjusted $\mathrm{R}^{2}$ & Cross-section year & Control for Utilization \\
\hline 0.256 & 0.123 & 0.930 & 96 & Yes \\
\hline 0.253 & 0.114 & 0.895 & 95 & Yes \\
\hline 0.286 & 0.126 & 0.912 & 94 & Yes \\
\hline 0.109 & 0.073 & 0.940 & 93 & Yes \\
\hline 0.239 & 0.112 & 0.937 & 92 & Yes \\
\hline 0.134 & 0.092 & 0.897 & 91 & Yes \\
\hline 0.129 & 0.124 & 0.889 & 90 & Yes \\
\hline 0.091 & 0.098 & 0.891 & 89 & Yes \\
\hline 0.382 & 0.197 & 0.909 & 88 & Yes \\
\hline 0.236 & 0.174 & 0.921 & 87 & Yes \\
\hline-0.118 & 0.117 & 0.887 & 86 & Yes \\
\hline-0.099 & 0.108 & 0.883 & 85 & Yes \\
\hline 0.307 & 0.262 & 0.883 & 84 & Yes \\
\hline 0.877 & 0.399 & 0.930 & 83 & Yes \\
\hline-0.140 & 0.130 & 0.926 & 82 & Yes \\
\hline 0.442 & 0.403 & 0.929 & 81 & Yes \\
\hline 0.282 & 0.290 & 0.893 & 80 & Yes \\
\hline 0.172 & 0.075 & 0.929 & 96 & No \\
\hline 0.203 & 0.078 & 0.894 & 95 & $\mathrm{No}$ \\
\hline 0.164 & 0.076 & 0.911 & 94 & $\mathrm{No}$ \\
\hline 0.048 & 0.045 & 0.939 & 93 & $\mathrm{No}$ \\
\hline 0.079 & 0.055 & 0.936 & 92 & No \\
\hline 0.069 & 0.060 & 0.896 & 91 & $\mathrm{No}$ \\
\hline 0.062 & 0.071 & 0.888 & 90 & No \\
\hline 0.077 & 0.078 & 0.890 & 89 & No \\
\hline 0.198 & 0.116 & 0.908 & 88 & No \\
\hline 0.119 & 0.106 & 0.920 & 87 & No \\
\hline-0.081 & 0.092 & 0.886 & 86 & $\mathrm{No}$ \\
\hline-0.072 & 0.086 & 0.882 & 85 & $\mathrm{No}$ \\
\hline 0.183 & 0.167 & 0.883 & 84 & No \\
\hline 0.171 & 0.134 & 0.929 & 83 & $\mathrm{No}$ \\
\hline-0.109 & 0.105 & 0.926 & 82 & No \\
\hline 0.141 & 0.197 & 0.928 & 81 & No \\
\hline 0.255 & 0.246 & 0.893 & 80 & No \\
\hline
\end{tabular}

Note: The same regression is run, either with or without allowing for capital utilization, for each cross-section year between 1980 to 1996. As with the pooled regressions, for any cross-section investment is observed from a plant's birth until the current cross-section year. In all regressions, industry dummies are included. 
Table 5

\begin{tabular}{|l|l|l|l|l|}
\cline { 2 - 5 } \multicolumn{1}{c|}{} & \multicolumn{4}{c|}{ Sample } \\
\hline Parameter & \multicolumn{1}{c|}{ POST72A } & \multicolumn{1}{c|}{ POST72B } & \multicolumn{1}{c|}{ SCREEN } & 72-96 PANEL \\
\hline$\gamma$ & $0.116(0.060)$ & $0.085(0.069)$ & $0.209(0.034)$ & $0.039(0.042)$ \\
\hline Intercept & $2.369(0.080)$ & $2.441(0.085)$ & $2.324(0.047)$ & $2.244(0.080)$ \\
\hline Multi & $0.080(0.008)$ & $0.098(0.006)$ & $0.059(0.005)$ & $0.083(0.012)$ \\
\hline$\beta$ & $0.319(0.005)$ & $0.354(0.004)$ & $0.324(0.001)$ & $0.299(0.005)$ \\
\hline$\Theta$ & $0.529(0.005)$ & $0.496(0.004)$ & $0.545(0.003)$ & $0.566(0.005)$ \\
\hline$\alpha$ & $0.114(0.005)$ & $0.112(0.004)$ & $0.099(0.002)$ & $0.088(0.004)$ \\
\hline$\eta$ & $0.018(0.004)$ & $0.019(0.004)$ & $0.025(0.001)$ & $0.028(0.003)$ \\
\hline$\tau$ & $2.219(0.105)$ & $1.909(0.055)$ & $2.731(0.092)$ & $6.569(1.397)$ \\
\hline \hline Adjusted $\mathrm{R}^{2}$ & 0.927 & 0.934 & 0.925 & 0.903 \\
\hline $\mathrm{N}$ & 96846 & 163191 & 224337 & 184678 \\
\hline
\end{tabular}

Note: All 4 columns refers to the full specification (i.e. that in Table 1, Column C). The "POST72B" regression also includes three dummy variables indicating whether the plant was born one year ago, two years ago, or three years ago. 


\section{Table 6}

\begin{tabular}{|c|c|c|c|}
\hline & $\mathrm{A}$ & $\mathrm{B}$ & $\mathrm{C}$ \\
\hline$\gamma$ & $0.332(0.319)$ & $-0.134(0.048)$ & $0.144(0.098)$ \\
\hline Intercept & $-0.030(0.980)$ & $1.519(0.029)$ & $2.494(1.006)$ \\
\hline$\alpha$ & $0.166(0.033)$ & & \\
\hline$\eta$ & $0.112(0.030)$ & & $0.049(0.010)$ \\
\hline Multi & $-0.269(0.047)$ & $0.058(0.011)$ & $0.947(0.006)$ \\
\hline Scale & & $0.939(0.007)$ & 1.000 \\
\hline $\begin{array}{c}\text { P-value for } \\
\text { Test of over- } \\
\text { identifying } \\
\text { restrictions }\end{array}$ & 1.000 & 1.000 & 0.906 \\
\hline \begin{tabular}{c} 
Adjusted $\mathrm{R}^{2}$ \\
\hline
\end{tabular} & 0.905 & & 0.905 \\
\hline
\end{tabular}

A: Regression with labor and materials elasticities measured by industry cost-shares.

B: Regression with all factor elasticities measured by industry cost-shares.

$\mathrm{C}$ : Average vintage regression with all factor elasticities measured by industry-level cost-shares.

Note: Regressions A-C also include year and industry dummy variables. 


\section{Table 7}

Annual Growth Rate from 1972-96

\begin{tabular}{|l|l|}
\hline Type of Equipment Capital Stock & Growth Rate \\
\hline A. This paper $--\gamma=11.6 \%$ & $14.7 \%$ \\
\hline B. This paper $--\gamma=7.7 \%$ & $11.2 \%$ \\
\hline C. This paper $--\gamma=0$ & $4.4 \%$ \\
\hline D. Conventional & $4.2 \%$ \\
\hline E. Hulten (1992) & $7.0 \%$ \\
\hline F. Greenwood, et al. (1997) & $7.0 \%$ \\
\hline
\end{tabular}

A -- The equipment capital stock implied by the $\gamma$ found in Table 1, Column C: $\gamma=0.116$ and the FRB physical depreciation schedules and the PCE deflator are used.

B -- $\gamma=7.7 \%$, FRB physical depreciation, and PCE deflator.

$\mathrm{C}--\gamma=0$, FRB physical depreciation, and PCE deflator.

$\mathrm{D}--\gamma=0$, BEA depreciation, and FRB/PPI investment deflators.

E -- $\gamma=3 \%$, BEA depreciation, and FRB/PPI investment deflators.

$\mathrm{F}--\gamma=3 \%$, BEA depreciation, and deflator for PCE of nondurables and nonhousing services. 


\section{FIGURE 1}

PCE deflator vs. average FRB equipment deflator used in our sample from 1972-96

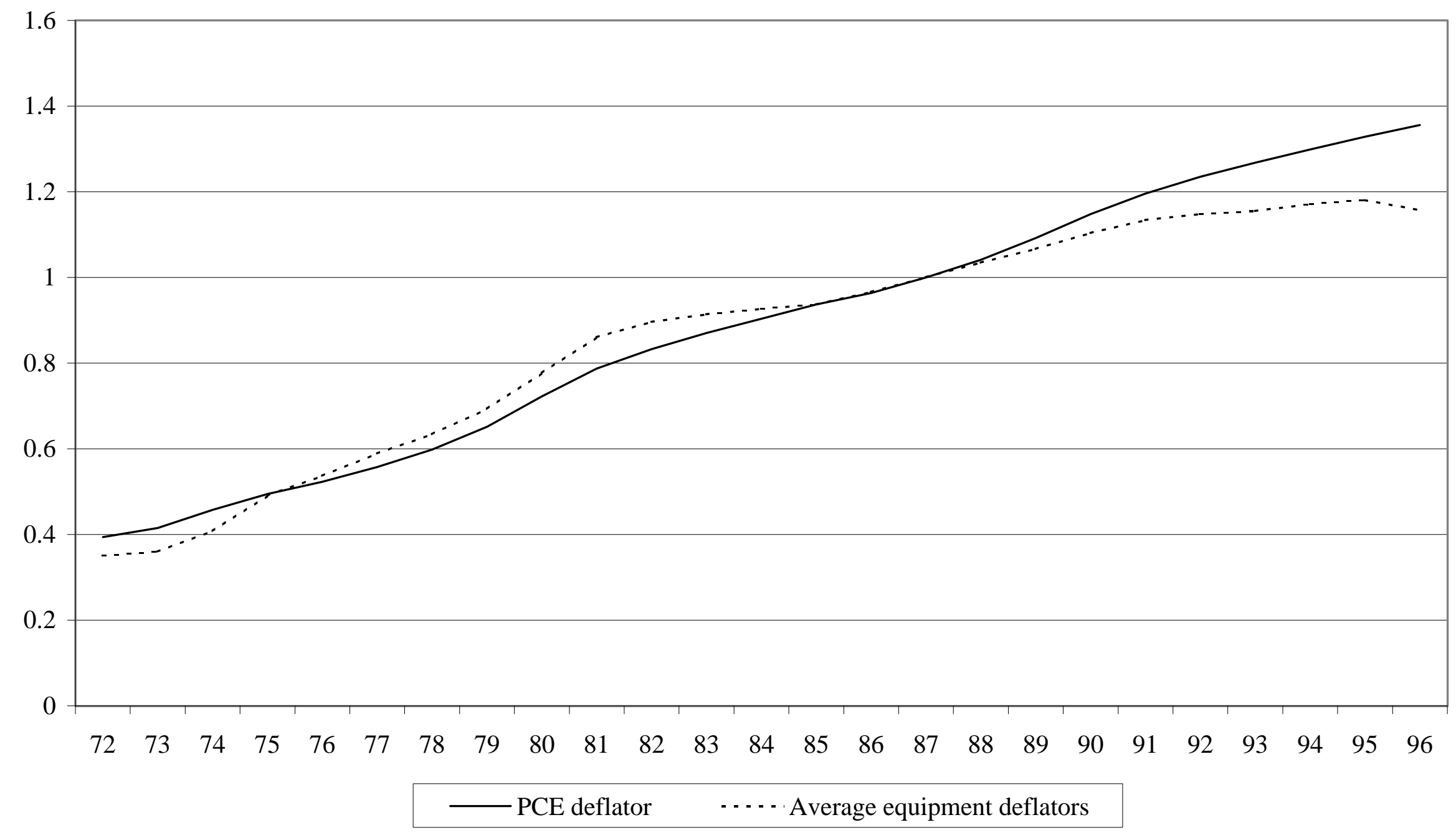


FIGURE 2

\section{Average Depreciation Pattern}

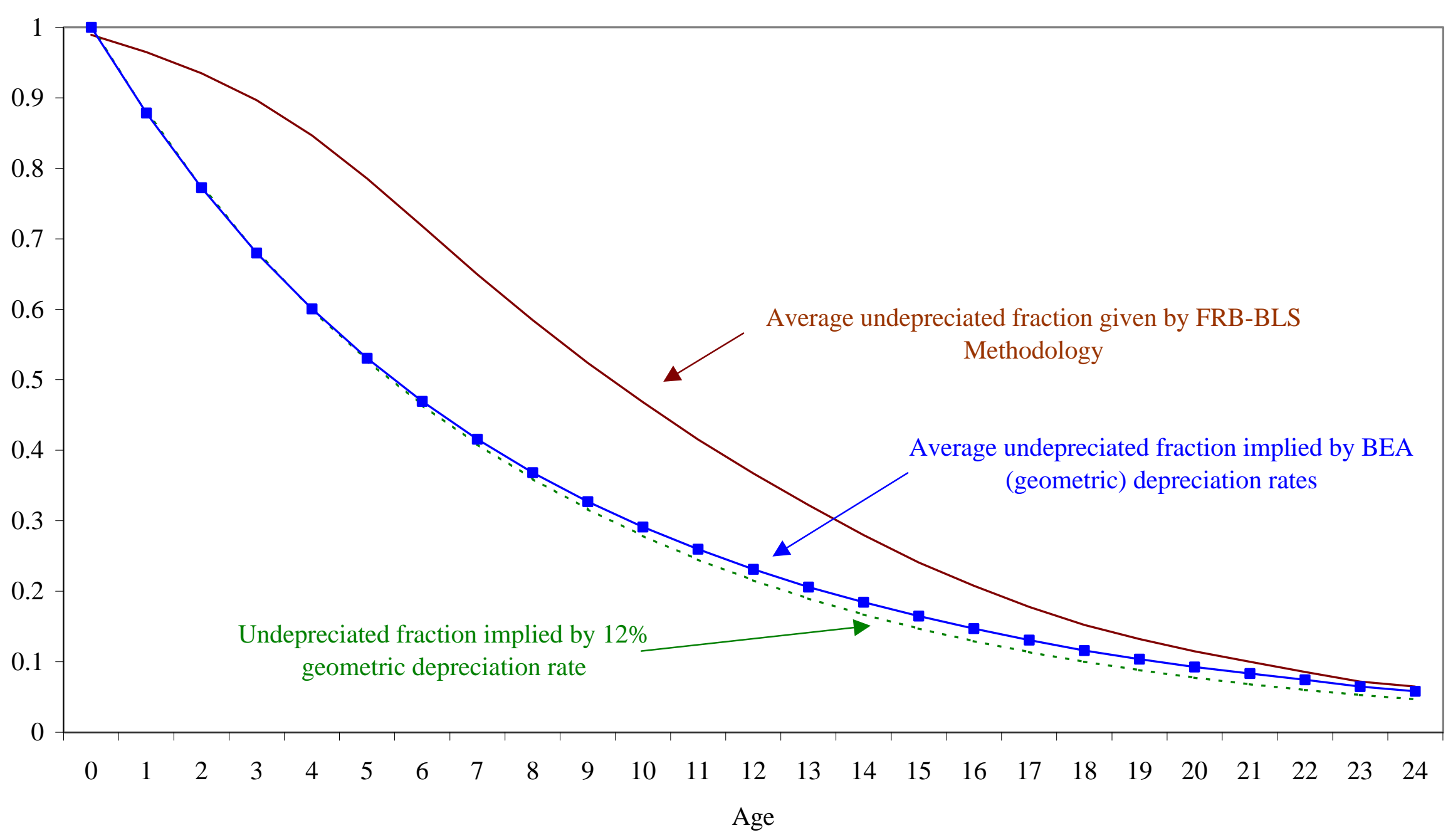




\section{Figure 3}

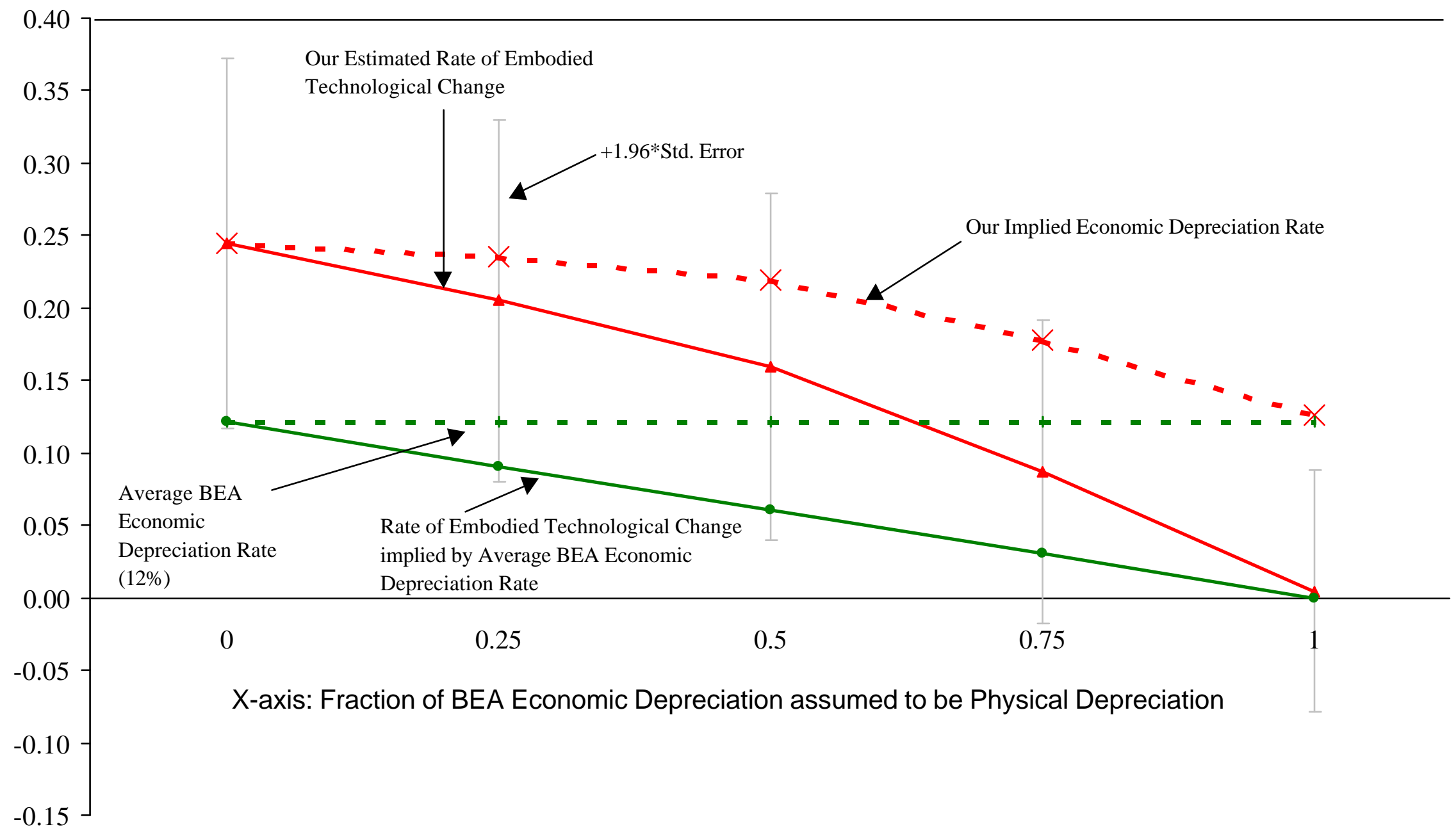


FIGURE 4

Percentage of All Mfg. Plants In Each Sample

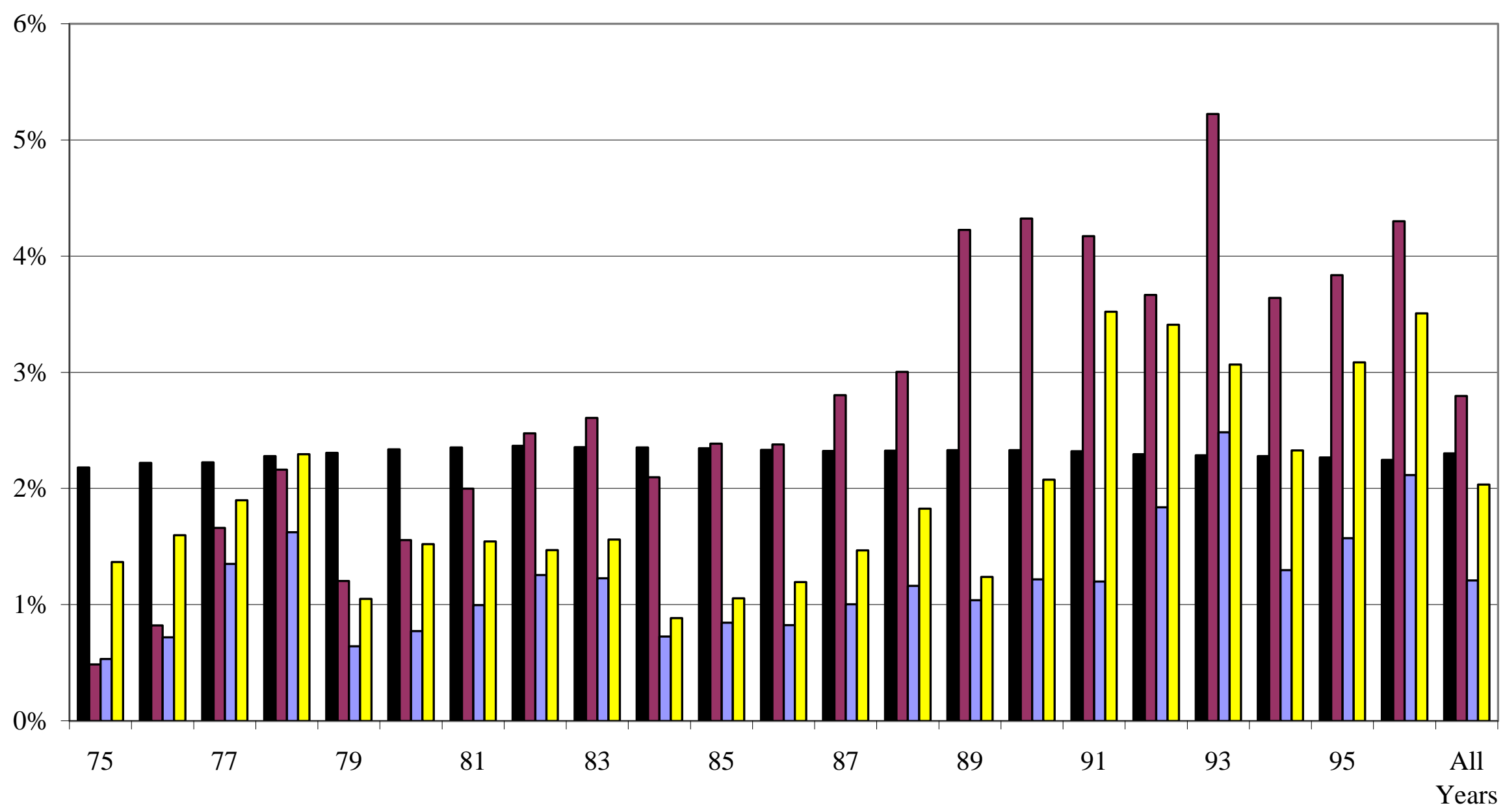

ם 72-96 Panel $\square$ SCREEN $\square$ POST72A $\square$ POST72B 
FIGURE 5

Percentage of Aggregate Mfg. Shipments Accounted For By Each Sample

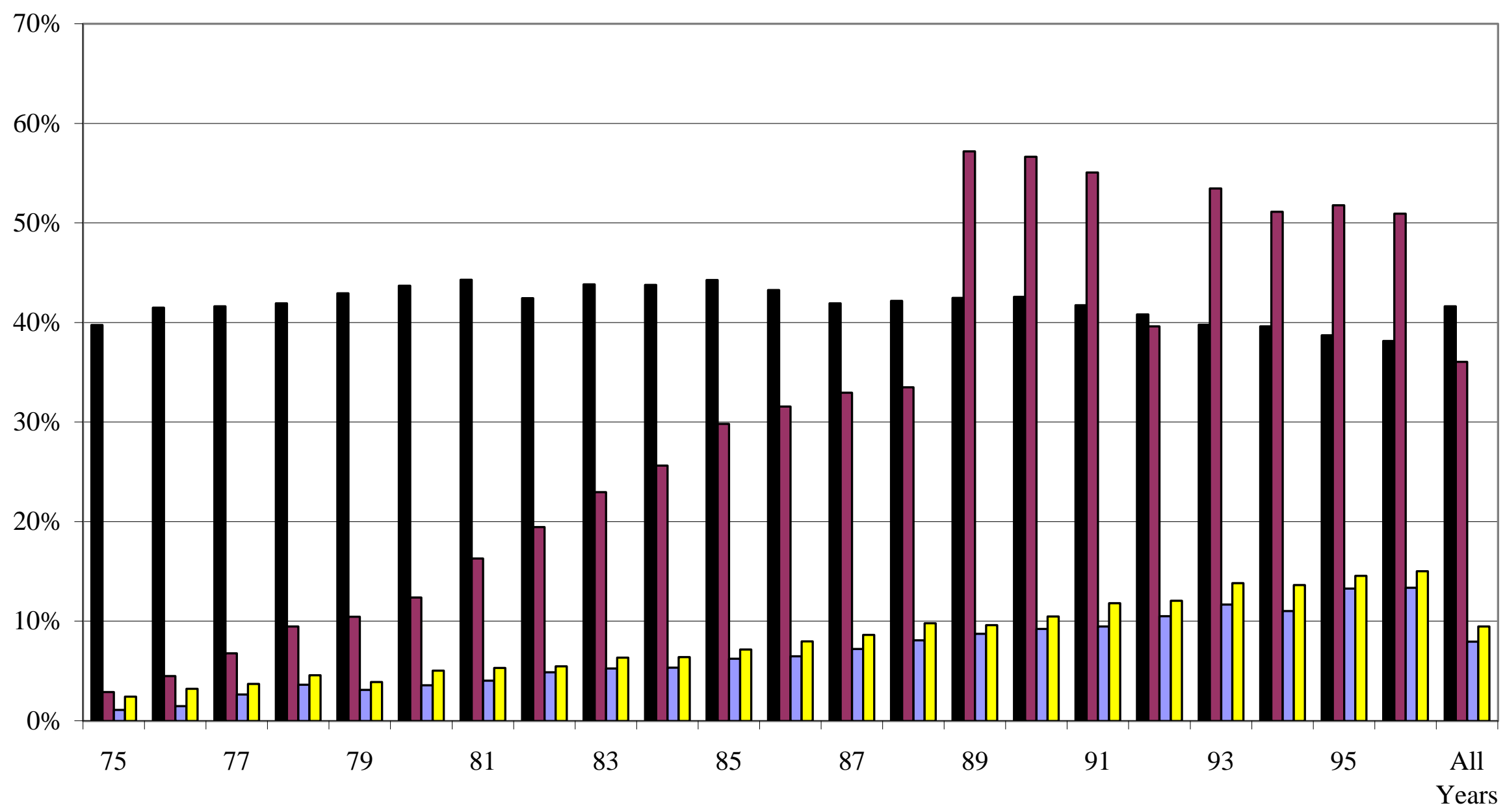

72-96 Panel $\square$ SCREEN $\square$ POST72A $\square$ POST72B 
FIGURE 6

Mean Plant Shipments (in \$1000)

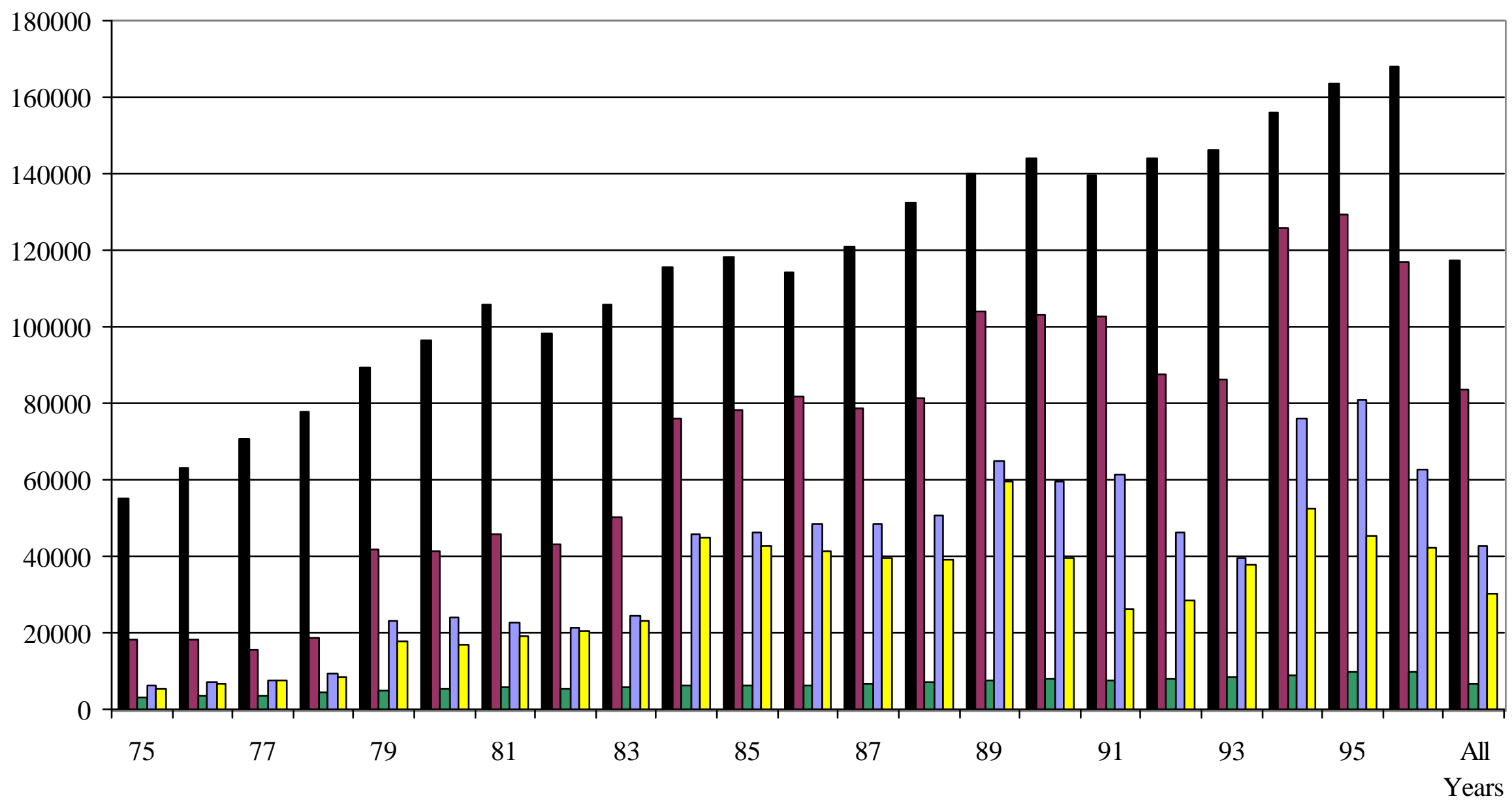

72-96 Panel $\square$ SCREEN $\square$ All Mfg. $\square$ POST72A $\square$ POST72B 
FIGURE 7

Average Age of Sample Plants By Year

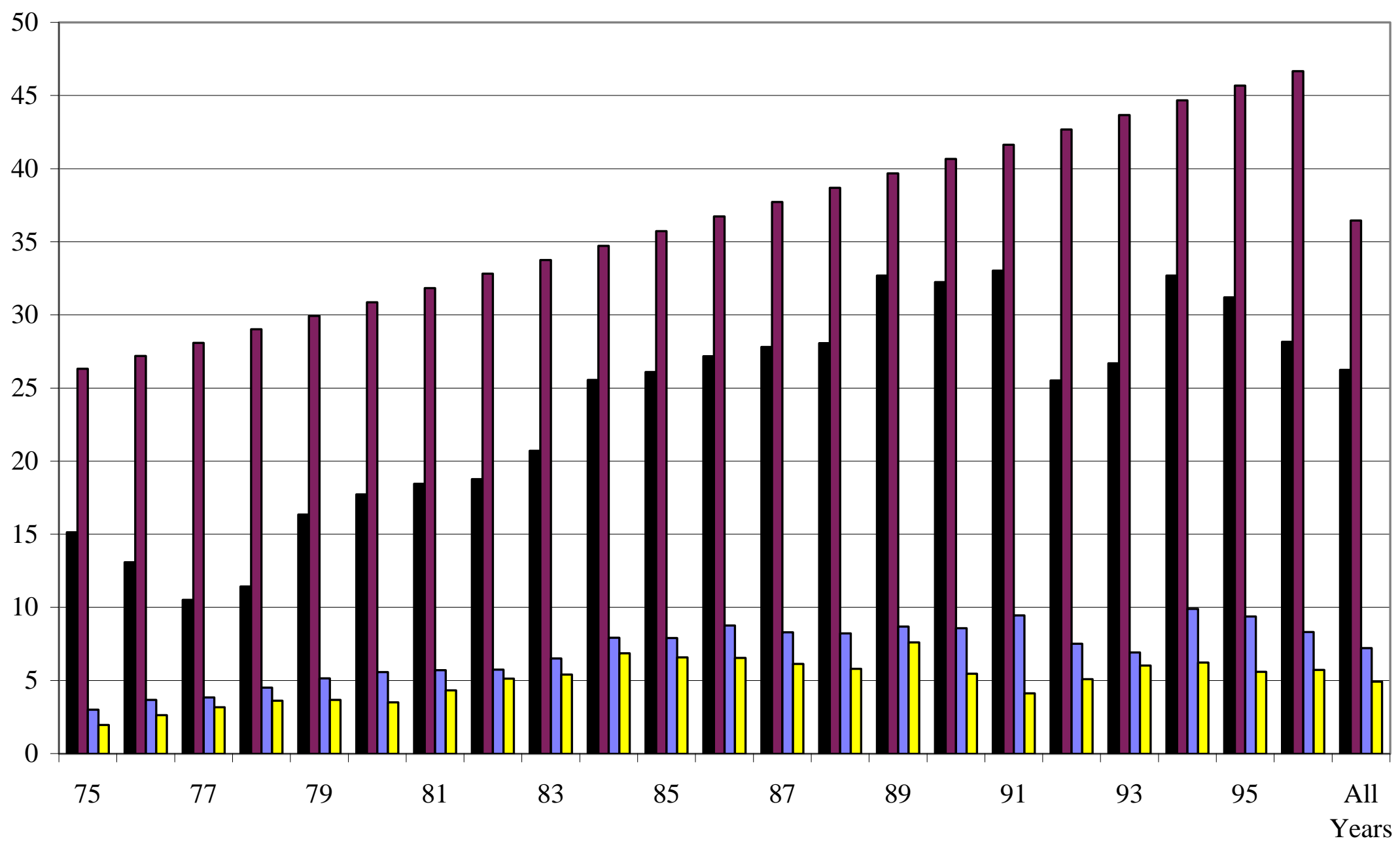

- SCREEN $\square$ 72-96 Panel $\square$ POST72A $\square$ POST72B 
FIGURE 8

1975-96 Mean 2-digit Industry Shares of Aggregate Mfg. Shipments For POST72A

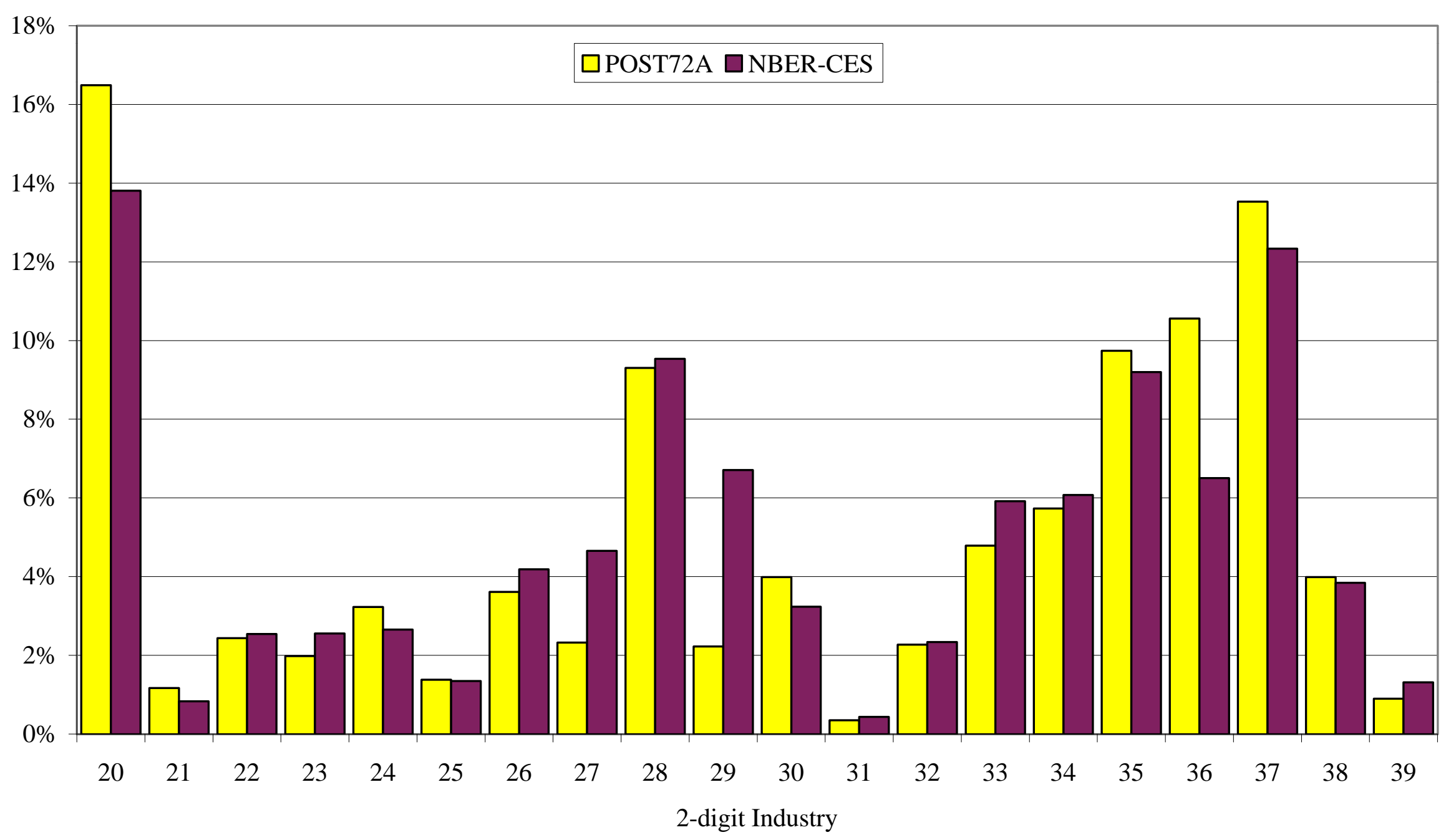


FIGURE 9

1975-96 Mean 2-digit Industry Shares of Aggregate Mfg. Shipments For POST72B

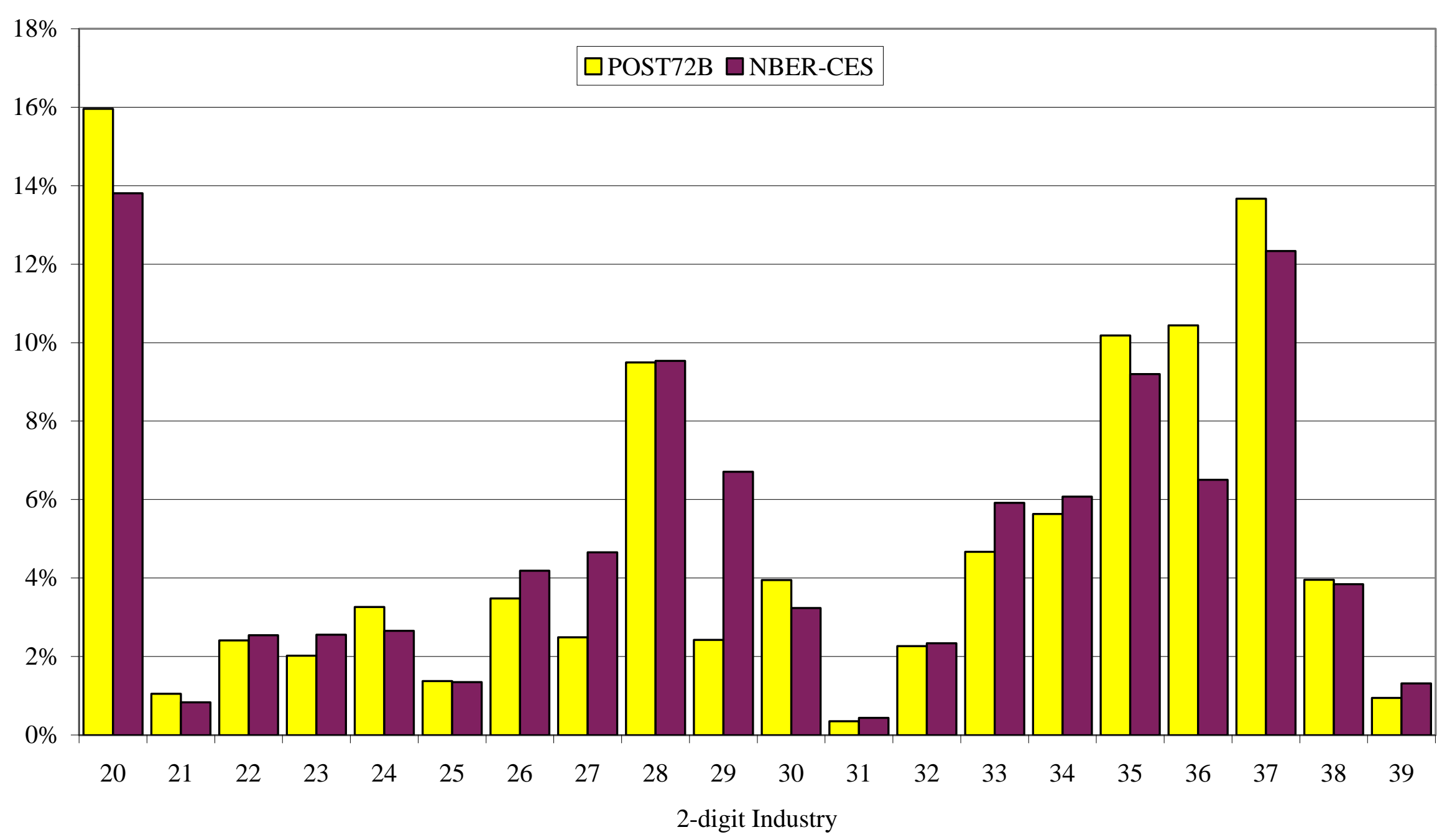


FIGURE 10

1975-96 Mean 2-digit Industry Shares of Aggregate Mfg. Shipments For 1972-96 Panel

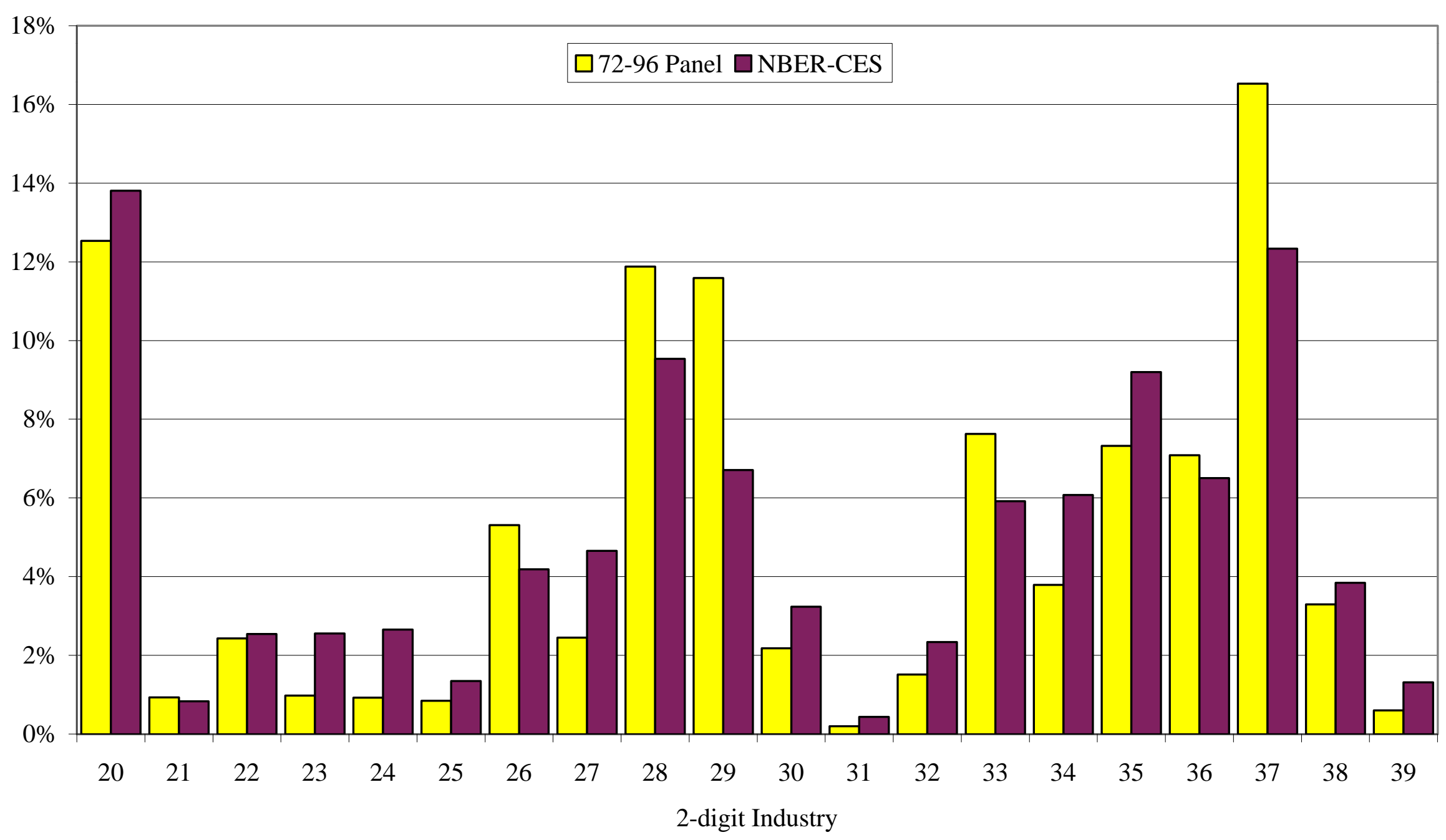


FIGURE 11

1975-96 Mean 2-digit Industry Shares of Total Mfg. Shipments For SCREEN

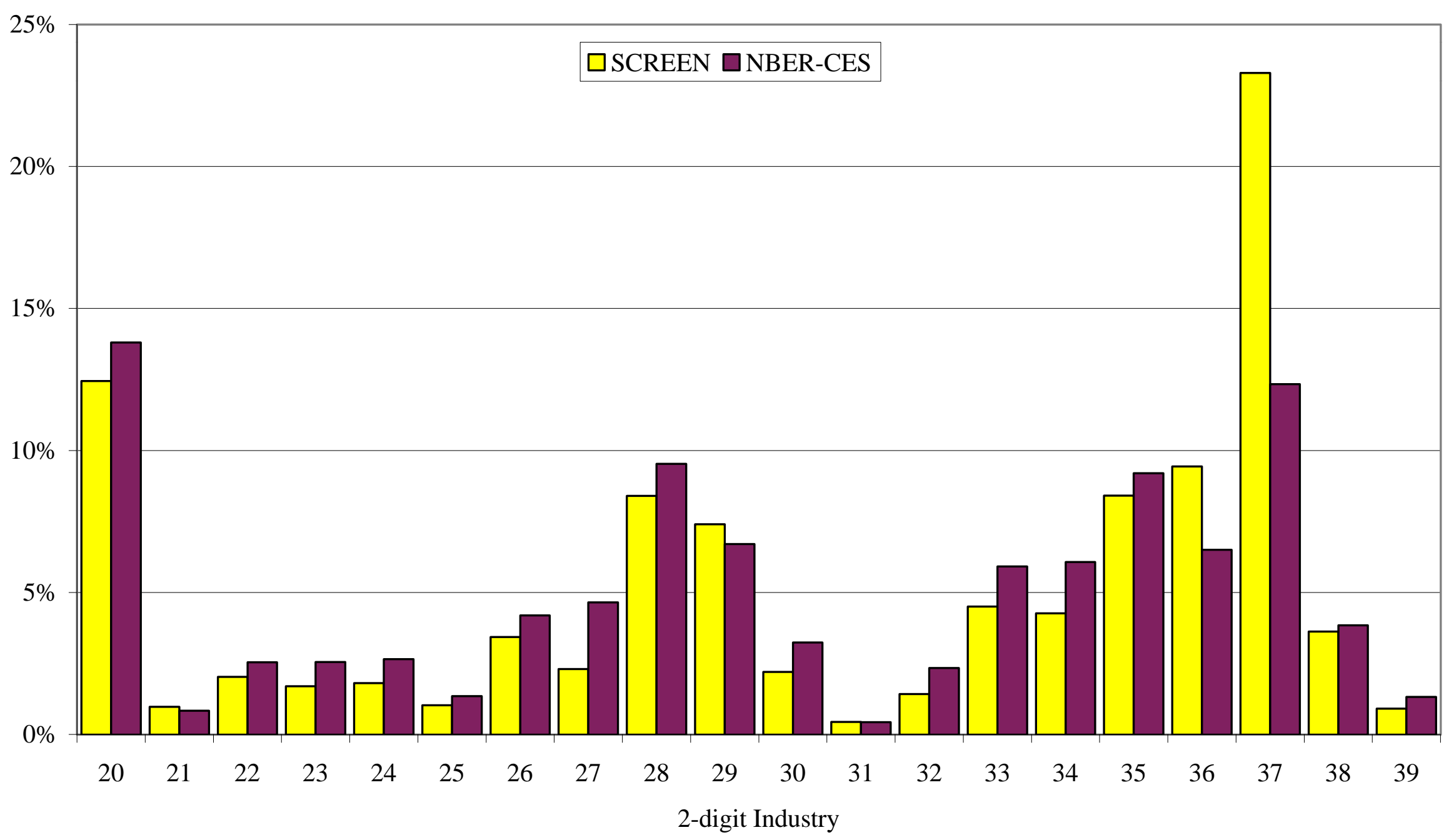


FIGURE 12

Employment Growth

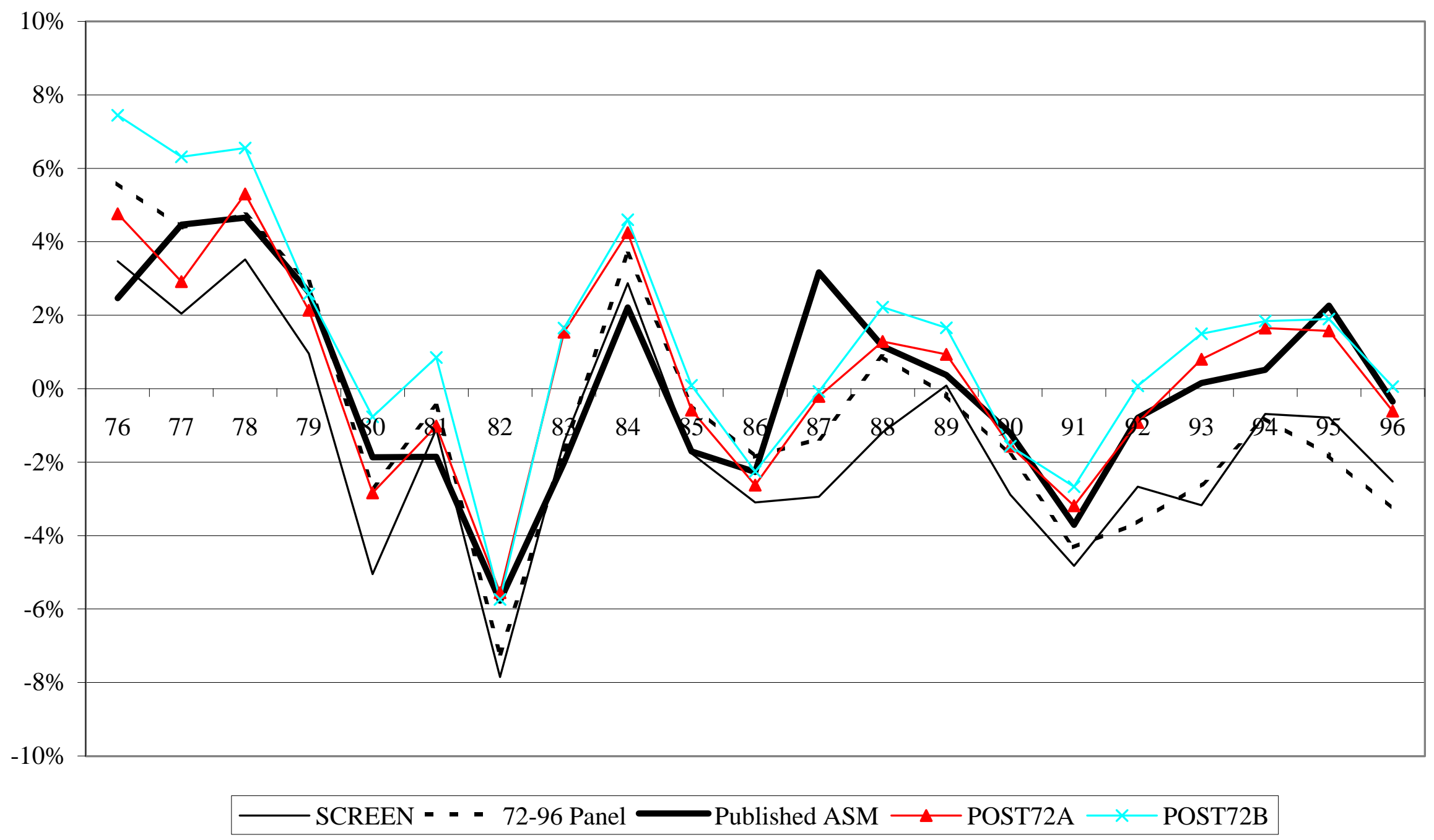


FIGURE 13

Growth Rates of New (Gross) Investment (Historical \$)

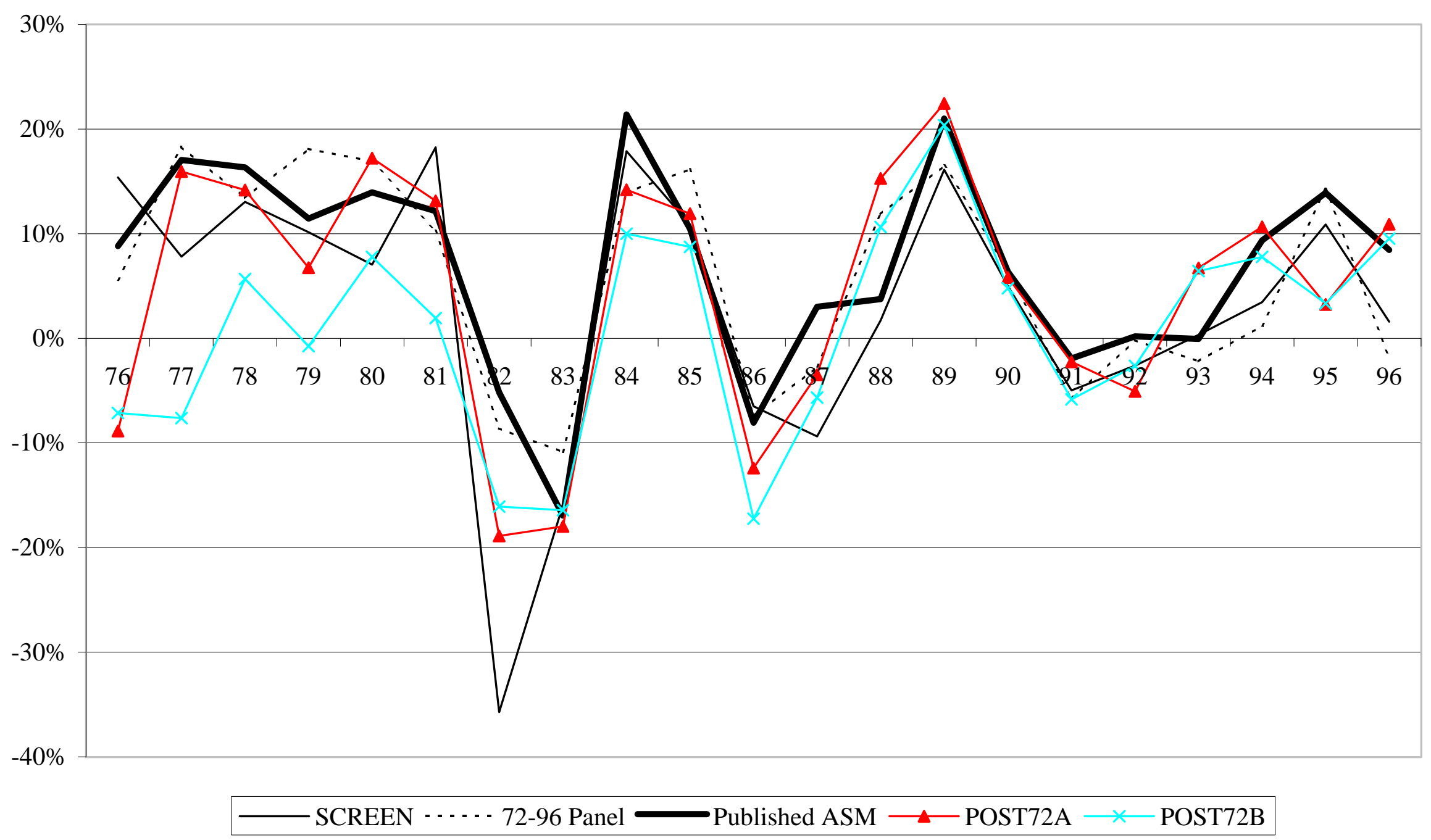

